\title{
Spillovers in Prices: The Curious Case of Haunted Houses*
}

\author{
Utpal Bhattacharya \\ Hong Kong University of Science and Technology \\ ubhattac@ust.hk \\ Daisy Huang \\ Southwestern University of Finance and Economics \\ daisy.vspe@gmail.com \\ Kasper Meisner Nielsen \\ Copenhagen Business School and HKUST \\ kmn.fi@cbs.dk
}

\begin{abstract}
$\underline{\text { Abstract }}$
Exploiting the unique institutional setting of Hong Kong's real estate market, we uncover a curious ripple effect of haunted houses on the prices of nearby houses. Prices drop on average 19\% for units that become haunted, $9 \%$ for units on the same floor, $6 \%$ for units in the same block, and $1 \%$ for units in the same estate. Our study makes two contributions. First, we provide an estimate of a large negative spillover on prices caused by an idiosyncratic quality shock. Second, we find that the demand shock rather than the fire sale supply shock explains most of the spillover.
\end{abstract}

JEL Classification: D62, H23, R21, R31, Key Words: fire sales, negative spillovers, haunted houses

\footnotetext{
* The authors are grateful to the Coroner's Court, and in particular to Information Officer Barry Lee, for providing administrative register data on unnatural deaths in Hong Kong from 2000 to 2015. This draft has benefited from excellent research assistance from Amit Kumar, Dalin Wang, Xiao Zhao and Zhuowei Hwang, and helpful comments and suggestions from discussants Johan Sulaeman and Ed Coulson, and from seminar participants at Aalto University, Australia National University, ABFER Conference 2018, Bank of Estonia, Chinese University of Hong Kong in Hong Kong and in Shenzhen, City University of Hong Kong, Erasmus University, FMA Asian Conference 2018, Goethe University Frankfurt, Harbin University, Hong Kong Baptist University, Hong Kong Polytechnic University, Hong Kong University of Science and Technology, Miami Behavioral Finance Conference 2017, Nanjing Audit University, Nottingham University Business School China, Peking University, Pontificia Universidad Javierana, Shanghai Advanced Institute of Finance, Southwestern University of Finance and Economics, Sun Yat-sen University (Guangzhou and Zhuhai), Tsinghua University, University of Amsterdam, University of British Columbia, University of Hong Kong, University of Oulu, University of Vaasa, and Zhejiang University. Send correspondence to Kasper Meisner Nielsen, Department of Finance, Copenhagen Business School, Copenhagen, Denmark; telephone: +45 3815 3601. E-mail: kmn.fi@cbs.dk.
} 


\section{Introduction}

Spillovers in prices occur in many financial markets, and are caused by an idiosyncratic shock that affects the price of just one asset, that in turn affects the price of other assets. Empirically it is challenging to identify shocks that are idiosyncratic, rather than systematic. Even when shocks are idiosyncratic, it remains a challenge to quantify how much of the spillover in prices is caused by the idiosyncratic demand shock or the idiosyncratic supply shock. ${ }^{1}$

The purpose of this paper is to employ a unique institutional setting that allows us to identify a well-defined idiosyncratic shock, and to isolate the effect of the demand and supply shocks in the spillover on prices. Specifically, we identify an idiosyncratic negative shock to the perceived quality of a house - a house being declared as "haunted" due to a murder, suicide or other unnatural death. This exogenous shock to perceived quality may cause a negative demand shock, a positive supply shock, or both. There will be a negative demand shock if the lower perceived quality makes prospective buyers reluctant to buy nearby houses, and there will be a positive supply shock if haunted house owners decide to sell their houses fast, resulting in price pressure. Both effects may cause the price of nearby houses to drop. Using the setting of haunted houses, we analyze the spillover effect on prices of neighboring houses, and examine whether it is driven by the fire sale of the haunted house (a supply shock) or lower perceived quality (a demand shock), or both. Contrary to prior literature, we can separate these two channels because the idiosyncratic quality shock (a house becoming haunted) and prices of nearby houses are observed, irrespective of whether the affected unit is sold or not.

\footnotetext{
${ }^{1}$ Prior empirical literature on spillovers in prices has been preoccupied with identifying the effect of fire sales on prices (see survey by Shleifer and Vishny, 2011) using transaction based data sets on airplanes (Pulvino, 1998), corporate bankruptcies (Eckbo and Thorburn, 2008; Bernstein et al, 2017), foreclosures (Campbell, Giglio, and Pathak, 2011: Anenberg and Kung, 2014), and mutual funds (Coval and Stafford, 2007). Collectively, these studies have established that fire sales lead to substantial reductions in prices, and result in negative spillover effects on prices of similar assets. Spillovers in prices, however, might occur not just due to the supply shock (price pressure) from a fire sale, but also from a demand shock.
} 
We analyze Hong Kong's residential real estate market because it offers four institutional features that help our identification strategy. First, since a population of 7.3 million (2015) lives in a small area that is less than $25 \%$ of its 1,106 square kilometers (most of the other area is reserved for country parks and nature reserves), residential real estate mainly consists of units in high rise blocks sharing common facilities on a small plot of land, called an estate. Although estates are heterogeneous, blocks within an estate and the units within a block are fairly homogenous. ${ }^{2}$ This helps in our identification because it makes spillovers in prices easier to identify, and allows us to control for unobserved heterogeneity in the cross-section of units as well as in the time-series.

Second, residents are very wary of haunted houses, and sellers have to disclose whether a house is haunted. ${ }^{3}$ In Hong Kong, the psychological component of the value of a house, given the beliefs of locals, is related to the principles of Feng Shui. An unnatural death, it is believed, causes excess negative energy, and impairs the value of a house. As a result, real estate companies maintain databases of haunted houses complied from local press reports covering these tragic events. ${ }^{4}$ The focus on haunted houses helps our identification, because unnatural death is an idiosyncratic negative shock to the perceived quality of the unit. Third, as the Hong Kong real estate market is very liquid and the flow of haunted houses is large in number (in our sample of liquid estates, from 2000 to 2015, 1,032 units were identified as haunted), we have a sample size with sufficient statistical power to detect spillovers in a small

\footnotetext{
${ }^{2}$ In our sample, each estate has an average of 12 blocks, each block has an average of 26 floors, and each floor has an average of 5 units. Thus, the average estate in our sample consists of 1,560 apartments in a small area.

${ }^{3}$ In Jopard Holdings Limited v. Ladefaith Limited and Centaline Property Agency Limited (HCA3775/2001), the Property Agent lost the case because "the Agent did not exercise reasonable care and skill in the collection and passing on of information concerning the Property." The information that was not revealed was the tragic death of a 4-year-old boy who had fallen from the balcony of the unit a year before the sale.

(http://legalref.judiciary.gov.hk/lrs/common/search/search_result_detail_frame.jsp?DIS=43673\&QS=\%2B\&TP=JU)

${ }^{4}$ See, for example, http://www.squarefoot.com.hk/haunted/
} 
geographic area with homogenous quality of units. ${ }^{5}$ Fourth, and finally, the institutional setting makes it unlikely that local market conditions differentially affect haunted and non-haunted units, floors or blocks within an estate, because of the close proximity. ${ }^{6}$ This bolsters our identification strategy and makes it reasonable to attribute the effect of haunted houses on the prices of nearby units to the spillover effect.

To examine the effect of haunted houses on prices, we follow a standard approach in real estate economics and regress the logarithm of the price on time-varying unit characteristics, unit fixed-effects, and year-month fixed effects. We find that the haunted unit drops in price by $19.0 \%$ after it becomes haunted; the units in the affected floor drop in price by $8.9 \%$; the units in floors 1 to 3 floors above or below the affected floor drop in price by $8.3 \%$; the units in floors 4 to 6 floors above or below the affected floor drop in price by $7.5 \%$; the units in the affected block drop in price by $6.2 \%$; the units in the block that is the neighbor of the haunted block drop in price by $3.3 \%$; the units in the affected estate drop in price by $1.3 \%$. Local economic shocks in Hong Kong cannot explain this highly granular ripple effect within an estate.

Amongst the tragic events that we consider, murder has the most dramatic ripple effect. Interestingly, price recovery is slow. We find that prices of the haunted units do not seem to recover during our 16-year sample period. The prices of its affected neighbors on the same floor do recover, albeit very slowly. The affected block and the affected estate even have further discounts as time goes by.

\footnotetext{
5 Andersen and Nielsen (2017), who use sudden deaths as the exogenous event to document price drops in houses that have fire sales, cannot analyze spillovers because of a small sample size.

6 Haunted houses provides an ideal solution to the identification problem. To quote Campbell, Giglio and Pathak (2011): "Ideally, we would like an instrument that influences foreclosures but that does not influence house prices except through foreclosures: however, we have not been able to find such an instrument."
} 
A legitimate issue is how we define a haunted house. In Hong Kong a haunted house is where an unnatural death occurred. According to this definition, a unit will not be considered haunted if the unnatural death occurred outside the unit. We check this hypothesis using a placebo test. We construct a placebo sample of unnatural deaths that occurred outside the home of the deceased (deaths in traffic accidents, accidental deaths during medical procedures and accidental deaths due to drowning). We find no discounts in units in this placebo sample, and neither do we find any negative spillovers on the prices of nearby houses. A second legitimate issue is that haunted houses due to deaths before 2000 are unobserved, but might affect prices in the $2000-2015$ period. We address this issue by re-running our tests for estates constructed after 2000. Our results do not change. A third legitimate issue is that house price growth might be different in locations with haunted houses. We address this concern by re-running our tests using high-dimensional location-time fixed effects. The inclusion of high-dimensional fixed effects also addresses potential concerns about pre-trends in house prices due to geographic location, because the spillover effects are estimated using variation in house prices within a location at a given time. Again, our results do not change.

Our main result is that most of the spillover effect in prices is driven by the demand shock caused by the perceived drop in quality. We document this by comparing the spillover effect when the affected unit is sold (supply shock and demand shock) to spillover effects when the affected unit is not sold (only demand shock). Both these spillover effects are the same for affected floors, for affected blocks, and for affected estates, implying that the demand shock is mostly responsible for the spillover. We corroborate this finding by examining transactions before and after the unnatural death. We notice that liquidity increases for units after they become haunted implying that there is a supply shock at the unit level. However, liquidity does not change for affected floors, for affected blocks, and for affected estates, implying that there is no supply shock at these levels, and so the spillover in prices is caused by the 
demand shock. To this end, our study is the first to identify an idiosyncratic shock that causes a spillover effect on prices primarily driven by a demand shock.

Our study contributes to a growing literature on spillovers in prices. Prior literature has documented that macroeconomic shocks cause spillover in prices of stock and bonds due to rebalancing of institutional investors (Jotikasthira, Lundblad and Ramadorai, 2012; Manconi, Massa and Yasuda, 2012) or due to similarity in investment style (Boyson, Stahel and Stulz, 2010). Bankruptcy announcements might cause return contagions, leading to distress events for strategic partners (Boone and Ivanov, 2012) and creditors with large exposures (Jorion and Zhang, 2009), or to increased interest rates for industry rivals (Hertzel and Officer, 2012). Financial contagion might also be propagated through liquidity and risk-premium channels as suggested by Longstaff (2010). In relation to these papers, our study identifies an idiosyncratic shock that causes a spillover effect on prices, which is primarily driven by a demand shock caused by a perceived drop in quality, rather than a supply shock caused by forced sales.

We also contribute to the literature in real estate economics studying (dis)amenity spillovers due to foreclosure (Lin, Rosenblatt and Yao, 2009; Campbell, Giglio, and Pathak, 2011; Anenberg and Kung, 2014), large house sizes (Leguizamon, 2010), home ownership (Coulson and Li, 2013), and urban revitalization (Rossi-Hansberg, Sartre and Owens, 2010). The study that is closest to ours is Anenberg and Kung (2014), who decompose spillover effects of foreclosures into a supply and demand effect. Their identifying assumption is that the demand effect occurs at the time of the eviction, while the supply effect occurs at the time of the foreclosure. In comparison, our identification comes from the timing of unnatural deaths. Our decomposition into supply and demand effects is based on the simple idea that there cannot be a supply effect if the haunted house is not sold. 
Understanding whether spillovers are driven by a demand or supply shock is important when addressing policy responses. Following the Great Recession in 2008, much of the commentary has focused on spillovers in house prices caused by fire sales in foreclosure auctions. To curb the supply effect, various proposals in government suggested a moratorium on fire sales (see discussion in Mian, Sufi and Trebbi 2015). The possibility that part of the spillover in house prices might result from a demand effect, i.e. lower perceived quality of houses in neighborhoods with foreclosures, has largely been ignored. If the demand effect is contributing to the spillover in prices, the appropriate policy response is to prevent evictions, rather than fire sales.

Our findings also bring up questions. First, how relevant are our findings for other assets? It is tempting to say that our results do not generalize to other assets or situations where the idiosyncratic shock is unrelated to superstitious beliefs. This criticism misses the point; all we are looking for is a wellidentified idiosyncratic shock and, in our case, that happens to be due to superstitious beliefs. Examples of spillover due to idiosyncratic shocks are common among other assets. In real estate, spillovers might be caused by a shock to the perceived quality of a neighborhood with foreclosures. In stock and bond markets, spillover might be caused by a shock to the perceived risk. For firms in a given industry, spillover effects occur when other firms face financial distress or when other firms are involved in environmental disasters like oil spills. To this end, our focus on haunted houses provides clear identification of an idiosyncratic shock, and further allows us to demonstrate that the spillover in prices can be caused by a demand shock rather than a supply shock.

Second, how can discounts of $20 \%$ be sustained in equilibrium? The answer is straightforward. The belief in Feng Shui is quite strong among Chinese, and the population in Hong Kong is about $94 \%$ Chinese. Caucasians make up at most $5 \%$ of the population in any district, implying that most buyers have a large disutility for haunted houses. The few prospective buyers that do not themselves get disutility 
for haunted houses will, however, care about the resale value of their houses, and the resale value is expected to be low because many future buyers dislike haunted houses.

Third, how relevant are our research findings for other parts of the world? We address this question in three ways. We search Factiva for newspaper articles from Australia, United Kingdom and United States using keywords related to unnatural deaths (murder, homicide, suicide, etc.) and real estate transactions (property, house, transaction, etc.). To ensure that we get an unbiased sample of newspaper articles, our search terms do not include keywords related to discount or price drops. We identified 101 newspaper articles featuring stories about the effect of unnatural death on house prices. For example, New York Times (Nov 24, 2016) interviewed Randall Bell, an economist who has consulted on the appraisals of notorious properties, like the homes of O. J. Simpson and Jon Benet Ramsey. According to Bell, the stigma can result in 25 percent lower prices. If we take an average of the quoted price effects in the 101 articles, we find that the value of affected units drops by 24 percent. The quoted discount is remarkably stable across countries. We find a 14 percent decline in Australia (18 articles), 25 percent in United Kingdom (20 articles), and 28 percent in United States (63 articles). In comparison, we find that affected units in Hong Kong decline by 19 percent following an unnatural death. In addition to anecdotal evidence from newspaper articles, the U.S. legal system, as in Hong Kong, makes it illegal for a seller to hide the fact that the property being sold has a reputation of being haunted. ${ }^{7}$ Prospective buyers in the U.S. can also check whether anyone has died at a given address using web-based services like the website, www.diedinhouse.com. This suggests that potential buyers find this information to be useful. We therefore conclude that house price discounts due to unnatural deaths are relevant outside of Hong Kong.

\footnotetext{
${ }^{7}$ In the case of Stambovsky v. Ackley, the Supreme Court of New York, Appellate Division, ruled in 1991 that a seller must disclose that a house has a reputation for being haunted when there is a fiduciary relationship or in cases of fraud or misrepresentation, because such a reputation impairs the value of the house.
} 
Section II presents our data, and explains the institutional setting surrounding residential real estate and haunted houses in Hong Kong. Section III presents the discount results, while Section IV considers whether discounts are driven by the demand channel, the supply channel, or both. Section V examines the external validity of our results. Section VI presents a placebo test, while Section VII considers alternative specifications that controls for differential trends in house prices by including highdimensional location-time fixed-effects. Section VIII concludes.

\section{Data}

\section{II.A. Estates in Hong Kong}

The residential real estate market in Hong Kong consists of a private and a public sector. This study focuses on the private sector, which represents around $50 \%$ of the market share. We exclude the public sector, because property values are distorted by large government subsidies and sales restrictions.

The institutional setting of Hong Kong's private market for residential real estate is helpful for our identification strategy. Due to Hong Kong's rugged topography with steep hills, buildable land is scarce. The scarcity of buildable land combined with population growth has led to pervasive construction of high-rise blocks, resulting in one of the highest population densities in the world. In the most densely populated district, Kwun Tong, around 57,000 people live per square kilometer of land. Economies of scale, combined with Hong Kong Government's monopoly on land, have led to large scale real estate developments that are referred to as estates. The typical estate consists of several identical high-rise blocks sharing amenities such as carparks, fitness center, shuttle buses, swimming pool, and security. Each block typically consists of 20 to 80 floors sharing a lobby area, while each floor is subdivided into four to eight units with shared access by elevators and staircases. This helps in our identification because it alleviates the concern that local market conditions differentially affect haunted and non-haunted units or floors or 
blocks within an estate, because units within a block are homogeneous and blocks are very close to each other and share the same amenities. These institutional features make it easier to convincingly identify spillovers in prices.

To understand the nature of an estate it is helpful to zoom into one: Dawning Views. We start with a drone view of Hong Kong. Hong Kong consists of three territories: Hong Kong Island, Kowloon and New Territories. These territories are further divided into districts. Hong Kong Island has four districts, Kowloon has five districts, and New Territories has nine districts. Appendix A1 shows a map of the 18 districts. Appendix A2 zooms in on one estate, Dawning Views, in the North District of the New Territories. Appendix A3 shows a picture of the blocks of Dawning Views. Appendix A4 gives the estate layout of Dawning Views, while Appendix A5 shows the floor plan of floors 8 to 17 in Block 12 of Dawning Views, which have 8 units per floor. Collectively, Appendix A2 to A5 visualize the advantage of using Hong Kong's residential real estate market to identify spillovers in prices and uncover whether spillovers are driven by demand shocks, supply shocks, or both.

Our data cover all private residential real estate transactions in Hong Kong between 2000 and 2015. There were 1,056,922 of them. The data are maintained by EPRC Ltd., a commercial real estate agency in Hong Kong, and the data are available for sale to the public. The data include the estate name and location, the address of the block, floor, and unit, some property characteristics, transaction date, and transaction price.

The average unit in Hong Kong costs 4.23 million HKD (541,000 USD), and has an interior size of 606.3 square feet (56.3 square meters), making Hong Kong one of the most expensive cities in the world with an average price of 6,209 HKD (791 USD) per square foot, equivalent to 66,833 HKD (8,514 USD) per square meter. Most transactions occur in the New Territories, followed by Kowloon and Hong 
Kong Island. There is a lot of heterogeneity in these real estate transactions. The median growth in unit prices is $8.8 \%$ per year in the period 2000 to 2015 , the $25^{\text {th }}$ percentile being $5.4 \%$ and the $75^{\text {th }}$ percentile being $12.6 \% .^{8}$

Although there are 7,352 estates in Hong Kong, we focus on the most liquid estates. A liquid estate is defined as an estate with 1,000 or more transactions over our sample period, equivalent to around 5 transactions per month. Following this definition, 211 estates are classified as liquid (2.9\% of all estates). Although this is a small fraction of all estates in our sample, more than half of the transactions $(57.5 \%)$ in our data are located in a liquid estate. Figure 1 shows that the market share of liquid estates has been almost constant over the sample period both in terms of number of transactions and value of transactions. Figure 2 shows that the prices per square foot in liquid and illiquid estates have followed a parallel trend, with the exception of 2011 and 2012 where prices of illiquid estates appreciated more than for liquid estates. We note that this difference is driven by location as properties on Hong Kong Island appreciated faster than units in Kowloon and New Territories during these years. We conclude from these two figures that our sample of transactions in liquid estates is fairly representative for the residential real estate market in Hong Kong.

Table 1 reports detailed descriptive statistics showing the difference between liquid and illiquid estates. Panel A of Table 1 shows that units in liquid estates are slightly smaller (592 vs. 628 square feet), younger (10.5 vs. 19.7 years), sell at lower prices (3.84 vs. 4.80 million HKD) and are cheaper (6,033 vs 6,467 HKD per square foot) compared to illiquid estates. These differences are statistically significant. Part of the difference in price can be attributed to location as most (least) liquid estates are in New Territories (Hong Kong Island)_-see Panel B of Table 1-and property prices in the New Territories

${ }^{8}$ We analyze units with at least two transactions in our sample period. The growth rate in unit price per year is calculated from the price of the first transaction to the price of the last transaction. 
compared to property prices in Hong Kong Island, due to the longer distance to the central business district around Victoria Harbor, are lower. The number of transactions across years, as seen in Panel C of Table 1, has an inverse U pattern in the period 2000 to 2015 for both liquid and illiquid estates. Panel D of Table 1 shows no seasonal pattern for both liquid and illiquid estates.

While we focus on the most liquid estates, there is substantial heterogeneity even in this subset. The largest estate in our sample of liquid estates, Mei Foo Sun Chuen, consists of 99 high-rise unit blocks with around 13,500 units. During our sample period, 13,867 units in Mei Foo Sun Chuen are sold for a total transaction value of 45.2 billion HKD (5.76 billion USD). The smallest estate in our sample of liquid estates, LaGrove, consists of only 542 units. During our sample period, 1,000 units in LaGrove are sold for a total transaction value of 2.7 billion HKD (340 million USD).

\section{II.B. Haunted Houses}

A haunted house is a house where an unnatural death occurred. Unnatural deaths include accidents, murder, and suicide. To cater to home buyers' wariness of haunted houses, property information websites and real estate agents in Hong Kong spend effort compiling databases on haunted houses. Property websites maintain their databases by tracking local news and make their data publicly accessible online to attract browsing flow. After inquiring with real estate agents and market participants, we conduct a comparison of different internet portals of real estate brokers and decide to draw on four of them with the longest lists. ${ }^{9}$ These data sources include for each incidence of unnatural death an event date, a description of the incident, and an address with varying degrees of detail. Appendix B1 gives a screenshot

\footnotetext{
9 The first is property.hk, the second is Squarefoot, the third is hk-compass.com and the fourth is Spacious. URLs of the four haunted house lists are: http://www.property.hk/unlucky.php, http://www.squarefoot.com.hk/haunted/ http://www.hk-compass.com/badfile.php, https://www.spacious.hk/en/hong-kong/resources/tragic-events.
} 
of one of these websites—Squarefoot—where the first page shows the tab called "Haunted House" and the second page gives the list of haunted houses. Appendix B2 gives a screenshot of another of these websites_-Spacious — where the first page shows the tab called "Haunted houses," the second page shows a spooky ghost, and the third page shows the exact location of a haunted house.

As the focus of our current research is the most liquid 211 estates, we extract haunted houses only in these estates from the territory-wide databases described above using a name-matching algorithm. Further, we manually confirm that the haunted houses picked up by the name-matching algorithm do indeed belong to the 211 estates. Since the property information websites track the same news, there is overlap among their haunted houses databases. We combine these records and remove duplicates, but retain information which may help us to identify the complete address of the haunted unit. We obtain 898 records of haunted houses in the 211 liquid estates from 2000 to 2015.

One big challenge in these 898 records is to locate the exact address where the tragic event occurred. Among the 898 incidents, the estate name is available for all. However, block number is available for $729(81 \%)$ of them, floor number is available for $434(48 \%)$ of them, and unit number is available only for a few of them. Fortunately for us, the Coroner's Court in Hong Kong, after receiving a request from us, decided to give us a list of all unnatural deaths in Hong Kong during the period 2000 to 2015. We merged this data set with our previous data set from the real estate websites for the liquid estates. Our number of haunted houses increased from 898 to 1,032. More importantly, we now have $100 \%$ of all addresses at the unit level.

Panel A of Table 2 classifies these 1,032 haunted houses according to the type of unnatural death that caused the house to become haunted. Suicides are the major reason that a house becomes haunted ( $88 \%$ of our sample). Accidents (7\% of the sample) are the second most common cause. Murder, on the 
other hand, accounts for only $2 \%$ of our sample. The residual $7 \%$ are classified as miscellaneous. This classification is important because, as we will see later, though the negative spillover effect is greatest for murder, it exists for all other classifications as well.

Panel B of Table 2 documents that in our sample most haunted houses are in the New Territories. Panel C of Table 2 shows that the flow of haunted houses into our panel data set from 2000 to 2015 has no particular trend over the years. Finally, Panel D of Table 2 shows the number of transactions that occur after a house becomes haunted. We report the number of transactions involving: i) haunted units (the unit where the death occurred), ii) haunted floors (units on the same floor as the haunted unit, excluding the haunted unit), iii) haunted blocks (units in the same block as the haunted unit, excluding the haunted unit and haunted floor), and iv) haunted estates (units in the same estate as the haunted unit, excluding the haunted unit, haunted floor, and haunted block). Panel D shows that a significant number of transactions (around one third) are of haunted units or occur in haunted floors, haunted blocks or haunted estates.

\section{Spillover in Prices}

Table 3 reports the average price per square foot before and after a unit becomes haunted. Panel A shows the average price in HKD per square foot for transactions occurring one year before to one year after, whereas Panels B and C report the same for the period of two and three years before and after, respectively. To control for time-trends in prices we also report the average price per square foot in the same district in the same period, and provide a difference-in-differences estimate of the effect of haunted houses on the price per square foot.

We notice from Panel A that the affected unit decreases in price by $2 \%$ from one year before to one year after the unit becomes haunted. This is much lower than for units in the district as a whole, 
where prices rise by $9 \%$ from one year before to one year after. The difference-in-difference is $-11 \%$. The ripple effect can be seen if we look at floors. The affected floor-here we remove the affected unit from the floor-decreases in price by $1 \%$ from one year before to one year after the floor becomes haunted. This is lower than for the floors in the district as a whole, where prices rise by $1 \%$ from one year before to one year after. The difference-in-difference is $-1 \%$ (rounding off error). The affected block - here we remove the affected floor from the block - increases in price by $1 \%$ from one year before to one year after the floor becomes haunted. This is slightly lower than for the blocks in the district as a whole, where prices rise by $3 \%$ from one year before to one year after. The difference-in-difference is $-2 \%$.

The ripple effect continues to be seen in Panel B (two years before to two years afterwards). The difference-in-difference is $-15 \%$ for the unit, $-5 \%$ for the floor and $-2 \%$ for the block. The ripple effect continues to be seen in Panel C (three years before to three years afterwards). The difference-in-difference is $-18 \%$ for the unit, $-6 \%$ for the floor and $-4 \%$ for the block. In addition, by comparing Panels $A, B$ and C, we observe that the price drops are not temporary for the affected units, floors, or blocks. They do not recover even after three years.

We now formally estimate the relationship between the price of houses and their characteristics using a hedonic regression. The main equation for estimating the haunted house price is specified in Equation (1), where the dependent variable is the $\log$ price, $y_{i t}$ of unit $i$ in year-month $t$.

$$
y_{i t}=\alpha_{i}+\beta_{t}+\gamma^{\prime} X_{i t}+\theta^{\prime} H_{i t>k}+\epsilon_{i t}
$$

Here $\alpha_{i}$ captures unit fixed effects, $\beta_{t}$ is a vector of year-month fixed effects, $X_{i t}$ is a vector of unit characteristics that change over time, and $H_{i t>k}$ is a vector of indicators for a haunted unit due to an unnatural death occurring in year $k$, where $t>k$. The purpose for $k$ is to differentiate the time of an unnatural death from that of a transaction. Any unnatural death before the transaction of unit $i$ in year- 
month $t$ will make $H_{i t>k}$ one. Unit characteristics that change over time in our sample are interior size (due to alterations) and block age. We are also interested in two other unit characteristics: whether the transaction is of a new unit (primary transaction) and whether the transaction includes allocated space in the carpark.

The vector of indicators, $\mathrm{H}_{\mathrm{it}>\mathrm{k}}$, are: "Haunted unit" is an indicator for haunted units (units in which an unnatural death occurred). "Haunted floor" is an indicator for units on the same floor as the haunted unit, but is set to zero for the haunted unit. "Haunted block" is an indicator for units on the same block as the haunted unit. It is set to the count of the number of haunted units in the block, but is set to zero for haunted units and all units on a haunted floor. "Haunted estate" is an indicator for units in the same estate as the haunted unit. It is set to the count of the number of haunted units in the estate, but is set to zero for haunted units, units on the haunted floor, and units on the haunted block. "Same block, proximity to haunted floor (1-3)" is an indicator for units that are 1 to 3 floors above or below a haunted floor in a haunted block. "Same block, proximity to haunted floor (4-6)" is an indicator for units that are 4 to 6 floors above or below a haunted floor in a haunted block. "Same estate, neighbour to haunted block" is an indicator for units that are in a block that is the neighbour to a haunted block.

Notice that the indicator variable is 1 or 0 for units or floors, but the indicator variable is the count or 0 for blocks or estates. The reason for this is that in our sample, though there are no more than one haunted unit per floor, there are sometimes more than one haunted unit per block, and sometimes more than one haunted unit per estate. Since the effects of haunted units occurring over time in a block or estate may cumulate, we use the count to ameliorate this.

The coefficients of interest in equation (1) are the different $\theta$ coefficients. A negative $\theta$ reveals the discount for being haunted, and if negative, the magnitude of $\theta$ reveals the percentage discount. 
Table 4 shows the results of the above estimation. Column (1) reveals that the haunted unit drops in price by $19.8 \%$ after it becomes haunted; the units in the affected floor-here the affected unit is excluded from the affected floor-drop in price by $9.7 \%$; the units in the affected block-here the affected floor is excluded from the affected block-drop in price by $7.1 \%$; and units in the affected estate-here the affected block is excluded from the affected estate-drop in price by $1.4 \%$. Notice that all price drops, though statistically significant, diminish in magnitude as we move geographically outwards from the affected unit. This confirms the ripple effect documented in Table 3.

Column (2) shows an even more granular spiral effect. The haunted unit drops in price by $19.8 \%$ after it becomes haunted; the units in the affected floor drop in price by $9.6 \%$; the units in floors 1 to 3 floors above or below the affected floor drop in price by $8.8 \%(6.7 \%+2.1 \%)$; the units in floors 4 to 6 floors above or below the affected floor drop in price by $8.1 \%(6.7 \%+1.4 \%)$; the units in the affected block drop in price by $6.7 \%$; and units in the affected estate drop in price by $1.4 \%$.

Column (3) shows another geographical spiral effect. It shows that the haunted unit drops in price by $19.0 \%$ after it becomes haunted; the units in the affected floor drop in price by $8.9 \%$; the units in the affected block drop in price by $6.5 \%$; the units in the block that is the neighbour of the haunted block drop in price by $3.3 \%(1.3 \%+2 \%)$; and units in the affected estate drop in price by $1.3 \%$.

Column (4) brings all these indicators together. We find that the haunted unit drops in price by $19.0 \%$ after it becomes haunted; the units in the affected floor drop in price by $8.9 \%$; the units in floors 1 to 3 floors above or below the affected floor drop in price by $8.3 \%(6.2 \%+2.1 \%)$; the units in floors 4 to 6 floors above or below the affected floor drop in price by $7.5 \%(6.2 \%+1.3 \%)$; the units in the affected block drop in price by $6.2 \%$; the units in the block that is the neighbour of the haunted block drop in price by $3.3 \%(1.3 \%+2.0 \%)$; the units in the affected estate drop in price by $1.3 \%$. 
As our sample of unnatural deaths that cause houses to become haunted begins in 2000, it is possible that the estimated spillover effects are biased because unnatural deaths before 2000 are unobserved and these may have spillover effects of their own. Column (5) corrects for this potential source of bias by restricting the sample to only new estates that are constructed during the sample period. By definition, new units start the count at zero when they enter our sample, ensuring that our methodology correctly counts the number of haunted units within an estate for this sample. As can be seen in column (5), though our sample size is much smaller, our results do not qualitatively change.

To conclude, a unit becoming haunted has a significant price drop, both economically and statistically. More importantly, price drops are seen for all units that are close to the haunted unit. The closer is the unit, the larger is the price drop. The fact that the negative externality dissipates away within an estate suggests that local Hong Kong economic shocks are unlikely to be responsible.

The coefficients on size and age have the expected signs. Larger units are valued more; older units are valued less. New units are valued more, as are units with carparks. The inclusion of unit-fixed effects takes care of all time-invariant unit characteristics. The year-month fixed effects controls for all marketwide demand and supply shocks over time.

Though Table 4 does show the ripple effect, it does not show whether the price drops are temporary or persistent. To do this we estimate Equation (2):

$$
y_{i t}=\alpha_{i}+\beta_{t}+\gamma^{\prime} X_{i t}+\theta^{\prime} H_{i t>k}+\lambda^{\prime} * \text { Time } * H_{i t>k}+\epsilon_{i t}
$$

Equation (2) is the same as Equation (1) with one extra term added: the interaction between Time and $H_{i t>k}$. Here Time is the difference between the transaction date and the date where the unit becomes haunted, i.e. time equals $t-k$ measured in years. For the interaction with haunted block and haunted estate, 
we use the timing of the last event whenever there are multiple haunted units in a block or estate. The coefficients of interest in Equation (2) are the different $\lambda$ coefficients. A positive $\lambda$ reveals that prices of discounted haunted houses recover over time, and if positive, the magnitude of $\lambda$ reveals the speed of recovery.

Table 5 shows the results of the above estimation. Column (1), which includes the entire sample, reveals that the price of the haunted unit does not seem to recover at all. Notice that the coefficient on the interaction term is 0.0052 and statistically insignificant. The affected floor-here the affected unit is excluded from the affected floor-does seem to recover about $0.36 \%$ per year after an immediate price drop of $10.4 \%$. The recovery is very slow. The affected block where the affected floor is excluded and the affected estate where the affected block is excluded do not seem to recover either. In fact, the coefficients are negative, suggesting there are further discounts as time goes by. This means that the discounts are not temporary, a result suggested by the difference-in-difference estimates documented in Table 3. Column (2), which includes only new estates, has similar results. In an unreported regression, we have further examined whether the spillover effects are persistent across transactions. Thus, rather than interacting the haunted house indicators with time (as in Equation 2 above), we interact the haunted house indicator with the transaction number sequence (after becoming haunted). We find results of similar magnitude, suggesting that price recovery over time and transactions is indeed slow.

It would be interesting to know which cause of death is associated with the largest drop in price, and which cause of death has the highest spillover effect on prices. ${ }^{10}$ The answers are given in Table 6.

\footnotetext{
10 We quote from an article in the New York Times (Nov 14, 2016): "In Hong Kong, this is a big deal. Many people believe that living in a place where someone committed suicide or, worse, was murdered, brings all sorts of bad fortune. Those units, even years after such a death occurred, are discounted around 20 percent, sometimes 50 percent if the death was particularly gruesome."
} 
The numbers in Table 6 come from the same estimation of Equation (1), except now the regressions are run for sub-samples related to cause of death.

Table 6 shows that murder has the most adverse effect on the price of a unit: the house price drops by $34.5 \%$. Murder also has the most negative adverse effect on neighbouring house prices. The units in the affected floor drop in price by $19.2 \%$, the units in the affected block drop in price by $10.2 \%$, and units in the affected estate drop in price by $4.7 \%$. The magnitudes of the drops are statistically significant, which is remarkable considering that our sample only includes 21 murders. Table 6 also shows that price drops for all types of unnatural deaths. These drops, though statistically significant, diminish in magnitude as we move geographically outwards from the affected unit. So the ripple effect occurs for all types of unnatural deaths.

\section{Disentangling Spillovers in Prices: Demand Shock vs Supply Shock (Price Pressure)}

To further our understanding of the spillover effects, we now examine the underlying channels. Prior literature recognizes that foreclosures of houses have negative spillovers on prices of neighboring houses because of two effects. The first effect is the demand shock, which occurs if foreclosures negatively affect the perceived quality of neighboring houses. The second effect is the supply shock, also called price pressure or fire sales, which occurs because potential buyers of houses in the neighborhood revise downwards their reservation prices when they observe discounted prices on foreclosed houses. Our research design allows us to disentangle these two effects, because the focal event is an idiosyncratic unnatural death, rather than the sale of the property.

It is useful to develop a simple model to illustrate the two underlying channels. As all the units in an estate are fairly homogenous, we model the demand for houses, D, as a function of price, P:

$$
\mathrm{D}=\mathrm{H}+\mathrm{k}-\mathrm{cP},
$$


where $\mathrm{H}$ is an indicator variable equal to $-\mathrm{a}$ for a haunted house and 0 otherwise, $\mathrm{k}$ is a constant and $\mathrm{c}$ is the price sensitivity of demand. Intuitively k captures among other things, the quality of the house, while H captures the drop in quality due to the unnatural death.

We model the short-term supply for houses, S, as

$$
S=F+j
$$

where $\mathrm{F}$ is an indicator variable equal to $+\mathrm{b}$ if there will be a fire sale and 0 otherwise, and $\mathrm{j}$ is a constant. Intuitively, $\mathrm{F}$ captures the additional supply effect due to a fire sale, while $\mathrm{j}$ implies that the short-term supply of houses is constant.

The above formulation takes into account the conventional assumption that demand is negatively affected by price, while short-term supply is unaffected by price because it takes time for units to be built. The new assumption is that haunted houses due to feng shui are perceived to be of low quality and so there is a drop in demand. Given these formulations of linear demand and supply curves, the equilibrium price of the house equals:

$$
P^{*}=\frac{[(H+k)-(F+j)]}{c}
$$

It follows that if a house becomes haunted, but the unit is not sold, the price of its neighbor's house drops by a/c. In Figure 3, this is the movement in price from X to Y. We call this the spillover because of the "demand shock". If a house becomes haunted and the affected unit is about to be sold at fire sale price Z, its neighbor's price drops by $(a+b) / c$. In Figure 3, this is the movement in price from X to Z. So the spillover because of the "supply shock (price pressure)" is the movement in price from Y to $\mathrm{Z}$, and this equals $\mathrm{b} / \mathrm{c}$. 
In our setting we can measure the spillover due to the "demand shock" - a/c - because we can observe the effect on price of neighboring houses before and after a house becomes haunted, but the haunted house is not sold. Similarly, we can measure the spillover due to the "demand shock" plus the "supply shock" - $(\mathrm{a}+\mathrm{b}) / \mathrm{c}$ - because we can observe the effect on price of neighboring houses before and after a house becomes haunted, and the haunted house is sold at a fire sale price. The spillover caused by the "supply shock (price pressure) - b/c - is then the difference between the latter spillover and the former spillover.

We now empirically separate the effect of "supply shock" and the effect of "demand shock" on the negative spillover in house prices.

The first methodology we employ is based on the intuition that a necessary condition for a "supply shock" (price pressure) is that liquidity dramatically increases after a unit becomes haunted. Figure 4 shows the fraction of haunted units sold per year before and after being haunted, the fraction of units on the same floor as the haunted unit (excluding the haunted unit) that are sold per year before and after, the fraction of units on the same block as the haunted unit (excluding the haunted unit and units on the haunted floor) that are sold per year before and after, and the fraction of units on the same estate as the haunted unit (excluding the haunted unit and units on the haunted floor and in the haunted block) that are sold per year before and after. The benchmark is the fraction of units in the same district that are sold per year before and after. The conclusion we draw from Figure 4 is that there is a supply shock for haunted units, but there is no supply shock for haunted floors or haunted blocks or haunted estates.

Table 7 shows the above results more formally. As in Figure 4, we measure liquidity as the fraction of haunted units, haunted floors and haunted blocks that are sold before and after the event. As in Table 3, we restrict ourselves to the difference in liquidity one year before to one year after, two years before 
to two years after, and three years before to three years after. Similar to Table 3, the benchmark is the difference in liquidity in the same district.

Panel $\mathrm{A}$ in Table 7 shows that the fraction of haunted units sold increased from $6.0 \%$ to $13.3 \%$ from one year before to one year after. The fraction of the control sample just increased from $7.2 \%$ to $7.3 \%$. The difference-in-differences is $7.2 \%$. Haunted units are sold disproportionately more. This suggest a "supply shock" caused by haunted units. What is interesting, however, is that the difference-indifferences for units in haunted floors is zero. There is no "supply shock" for haunted floors. The difference-in-differences for units in haunted blocks is negative, which implies that there is no "supply shock" for haunted blocks either. The results are the same when we look at Panel B (two years before to two years after) and in Panel C (three years before to three years after): there is a supply shock for haunted units (though that attenuates over time), but there is no supply shock for haunted floors or haunted blocks.

The second methodology we employ is a regression framework. We estimate Equation (6):

$$
y_{i t}=\alpha_{i}+\beta_{t}+\gamma^{\prime} X_{i t}+\theta H_{i t>k}+\lambda * \text { Haunted Unit Sold } * H_{i t>k}+\epsilon_{i t},
$$

Equation (6) is the same as Equation (1) with one crucial difference: the interaction between Haunted Unit Sold and $H_{i t>k}$. Here Haunted Unit Sold takes a value of one if an affected unit is sold after the unnatural death. Equation (6) is estimated for the whole sample, as well as for three subsamples: if the unit is sold in the last year, in the last 3 years, and in the last 5 years.

The coefficients of interest in (6) are $\theta$ and $\lambda$. A negative $\theta$ reveals the immediate percentage drop in prices of neighbouring houses that is due only to the "demand shock" caused by a change in perceived quality of the neighbourhood. A negative $\lambda$ reveals the percentage drop in prices of neighbouring houses 
that is due only to the "supply shock" which is the price pressure caused by the fire sale of the affected unit.

Table 8 shows the results of the above estimation. Column (1) reveals that the affected floor here the affected unit is excluded from the affected floor - sees an immediate price drop of 9.9\% ( $\theta$ ) after the floor becomes haunted. The coefficient of the interaction term between the indicator for haunted house and the indicator for whether the affected unit is sold is negative, but statistically insignificant. This reveals that for the floor the discount is coming from mainly the demand shock caused by a perceived drop in quality of units on the affected floor. The affected block-here the affected floor is excluded from the affected block — sees an immediate price drop of $8.5 \%(\theta)$, and a price gain of $1.4 \%(\lambda)$ if the affected unit is sold. This reveals that for the block the discount is coming also mainly from the demand shock caused by a perceived drop in quality of units on the affected block. The affected estate-here the affected block is excluded from the affected estate-sees an immediate price drop of $2.2 \%(\theta)$, and a price gain of $0.8 \%(\lambda)$ if the affected unit is sold. This reveals that for the estate the discount is coming also mainly from the demand shock caused by a perceived drop in quality of units on the affected estate.

Columns (2), (3) and (4) show the results of the above test, respectively, for three subsamples: if the unit is sold in the last year, in the last 3 years, and in the last 5 years. The results are similar. Interestingly, if there was a supply shock effect, we would see a negative $\lambda$ everywhere, especially if the haunted unit is sold in the last year. We do not see any significantly negative $\lambda$ s in column (2). We do not see any significantly negative $\lambda \mathrm{s}$ in columns (3) or (4) either.

The conclusion from the above results is that negative spillovers in house prices caused by haunted houses is mostly a "demand shock" phenomenon. The main caveat with this interpretation is that haunted units might depress prices of neighbouring houses if they are listed, but ultimately not sold. While this 
remains a possibility, the results in Table 5 show little recovery in prices of neighbouring houses even after many years after units become haunted. This suggest that listing without sale cannot drive our results, because listings without sale are unlikely to exist for so many years. We therefore conclude that supply shocks, or price pressure, is not responsible for the spillover effects. Either the $\lambda$ coefficients are insignificant, or they are small, significant, and have the wrong sign. Notice that for affected floors, there is no effect of supply shock (price pressure) in any of the columns. For affected blocks and affected estates, the $\lambda$ coefficients become more positive as the sale of the haunted unit is further in the past. It is quite likely that this is because of the further price discounts noticed in Table 5 for affected blocks and affected estates.

The results in Table 8 suggest that the "demand shock" is the main explanation for negative spillovers. That corroborates our finding from Table 7 and Figure 4. In both Table 7 and Figure 4, we only saw a liquidity increase for the affected unit, but no change in liquidity for the affected floor, block or estate. In other words, there seems to be no "supply shock" (price pressure) for the affected floor, block or estate.

\section{External Validity}

How relevant are our research findings for other parts of the world? In Hong Kong, the psychological component of the value of a house, given the beliefs of locals, is related to the principles of Feng Shui. An unnatural death, it is believed, causes excess negative energy, and impairs the value of a house. This naturally raises the question of the external validity of our findings.

We address this question in three ways. First, we search Factiva for newspaper articles from Australia, United Kingdom and Unites States using keywords related to unnatural deaths (murder, homicide, suicide, etc.) and real estate transactions (property, house, transaction, etc.). To ensure that we 
get an unbiased sample of newspaper articles, our search terms do not include keywords related to discount or price drops. We identified 101 newspaper articles featuring stories about the effect of unnatural death on house prices. For example, New York Times (Nov 24, 2016) interviewed Randall Bell, an economist who had consulted on the appraisals of notorious properties, like the homes of O. J. Simpson and Jon Benet Ramsey. According to Bell, the stigma can result in 25 percent lower prices. If we take an average of the quoted price effects in the 101 articles, we find that the value of affected units drops by 24 percent. The quoted discount is remarkably stable across countries. We find a 14 percent decline in Australia (18 articles), 25 percent in United Kingdom (20 articles), and 28 percent in United States (63 articles). In comparison, we find that affected units in Hong Kong decline by 19 percent following an unnatural death.

Second, we find that in the U.S. legal system, as in Hong Kong, it is illegal for a seller to hide the fact that the property being sold has a reputation of being haunted. Third, we find that web-based services like the website, www.diedinhouse.com, help potential buyers in the U.S. to find out if anyone has died at a given address. This suggests that potential buyers find this information to be useful. Based on these three findings, we conclude that house price discounts due to unnatural deaths are relevant outside of Hong Kong.

\section{A Placebo Test}

A legitimate issue to revisit at this stage is how we define a haunted house. A haunted house is where an unnatural death occurred. According to this definition, a unit will not be considered haunted if the unnatural death occurred outside the unit. We now test this proposition by doing a placebo test.

The treatment sample of 1,032 unnatural deaths is from our baseline specification in Column 1 of Table 4. The placebo sample (coded in similar fashion as the treatment sample) are 235 unnatural 
deaths that occur outside the residence of the deceased. We obtain information on these deaths from the Coroner's Court as they do not feature on the real estate websites tracking haunted houses. The placebo sample consists of 183 deaths in traffic accidents, 23 accidental deaths during medical procedures, and 29 accidental deaths due to drowning while swimming in the ocean.

We estimate Equation (1) separately for the treatment sample and for the placebo sample. Column (1) of Table 9 gives the coefficients of the treatment sample. The signs and magnitudes of the $\theta$ coefficients are similar to the signs and magnitudes of the $\theta$ coefficients in column (1) of Table 4. Column (2) of Table 9 gives the coefficients of the placebo sample. The $\theta$ coefficients are either insignificant or positive and significant. This tells us that when the resident of a unit dies outside the unit, there is no discount on the unit's price and no spillover effect on nearby houses. This is consistent with our conclusion that a house becomes haunted and is discounted only when there is an unnatural death in the house.

\section{Alternative specifications}

In this section, we address concerns related to the identification strategy and the hedonic pricing

model. A potential concern with the specification in equation (1) is that haunted houses are located in different areas than houses that are unaffected. If the demand for houses and/or the supply of houses in these locations are different, time-varying location effects might drive the results.

For instance, one might be concerned that suicides or murders occur in specific neighborhoods that have differential trends in house prices. If the house price growth is slower in these districts, this effect might confound the estimated spillover effects in prices. 
We address the concern that our results are driven by slower price growth in affected districts by introducing high-dimensional fixed-effects to control for time-variant location effects. Table 10 reports the results, when we change the estimation (1) to

$$
y_{i t}=\alpha_{i}+\beta_{j t}+\gamma^{\prime} X_{i t}+\theta^{\prime} H_{i t>k}+\epsilon_{i t}
$$

Here $\alpha_{i}$ captures unit fixed effects, $\beta_{j t}$ captures location-time fixed effects, $X_{i t}$ is a vector of unit characteristics that change over time, and $H_{i t>k}$ is a vector of indicators for a haunted unit due to an unnatural death occurring before year $t$. Table 10 reports results. Column 1 shows the results from the baseline specification in Column 1 of Table 4. We note that although the coefficients in Columns 2 to 5 are slightly smaller than in Column 1, the results are qualitatively similar, when we include location-time fixed effects, both at the territory and district level. We conclude that our results are unaffected when we include high-dimensional fixed-effect that effectively controls for the development in house prices at different locations over time. These high-dimensional fixed effects also addresses potential concerns about pre-trends in house prices due to geographic location, because the spillover effects in Table 10 are estimated using variation in house prices within a location at a given time.

\section{Conclusion}

Empirically it is difficult to convincingly conclude that price drops for houses are being caused by a negative shock in a neighboring house without completely ruling out that shocks to the local economy are affecting both. The first contribution of our study is that we exploit the unique institutional setting of Hong Kong's residential real estate to overcome this identification problem. We uncover a curious ripple effect of haunted houses on the prices of nearby houses. Prices drop on average 19\% for units that become haunted, $9 \%$ for units on the same floor, $6 \%$ for units in the same block, and $1 \%$ for units in the same estate. The ripple effect is strongest for murders. Price recovery is slow. 
The second, and more important contribution of our paper, is that since we observe that negative spillovers exist even if the haunted house is not sold, we can isolate the demand shock channel from the supply shock (price pressure) channel. We find that the demand shock caused by a perceived drop in quality explains most of the spillover. 


\section{REFERENCES}

Andersen, S., Nielsen, K.M., 2017. Fire sales and house prices: Evidence from estate sales due to sudden death. Management Science 63, 201-212.

Anenberg, E., Kung, E., 2014. Estimates of the size and source of price declines due to nearby foreclosures. American Economic Review 104, 2527-2551.

Bernstein, S., Colonnelli, E., Giroud, X., Iverson, B., 2017. Bankruptcy spillovers. NBER working paper no. w23162.

Boone, A.L., Ivanov, V.I., 2012. Bankruptcy spillover effects on strategic alliance partners. Journal of Financial Economics 103, 551-569.

Boyson, N.M., Stahel, C.W., Stulz, R.M., 2010. Hedge fund contagion and liquidity shocks. Journal of Finance 65, 1789-1816.

Campbell, J.Y., Giglio, S., Pathak, P., 2011. Forced sales and house prices. American Economic Review 101, 2108-2131.

Coulson, N.E., Li, H.R., 2013. Measuring the external benefits of homeownership. Journal of Urban Economics 77, 57-67.

Coval, J., Stafford, E., 2007. Asset fire sales (and purchases) in equity markets. Journal of Financial Economics 86, 479-512.

Eckbo, B.E., Thorburn, K.S., 2008. Automatic bankruptcy auctions and fire-sales. Journal of Financial Economics 89, 404-422.

Hertzel, M.G., Officer, M.S., 2012. Industry contagion in loan spreads. Journal of Financial Economics 103, 493-506.

Jorion, P., Zhang, G.Y., 2009. Credit contagion from counterparty risk. Journal of Finance 64, 20532087.

Jotikasthira, C., Lundblad, C., Ramadorai, T., 2012. Asset Fire Sales and Purchases and the International Transmission of Funding Shocks. Journal of Finance 67, 2015-2050.

Leguizamon, S., 2010. The influence of reference group house size on house price. Real Estate Economics 38, 507-527.

Lin, Z., Rosenblatt, E., Yao, V., 2009. Spillover Effects of Foreclosures on Neighborhood Property Values. Journal of Real Estate Finance and Economics 38, 387-407

Longstaff, F.A., 2010. The subprime credit crisis and contagion in financial markets. Journal of Financial Economics 97, 436-450.

Manconi, A., Massa, M., Yasuda, A., 2012. The role of institutional investors in propagating the crisis of 2007-2008. Journal of Financial Economics 104, 491-518.

Mian, A., Sufi, A. and Trebbi, F., 2015, Foreclosures, house prices, and the real economy, Journal of Finance 70, 2587-2634.

Pulvino, T.C., 1998. Do asset fire sales exist? An empirical investigation of commercial aircraft transactions. Journal of Finance 53, 939-978.

Rossi-Hansberg, E., Sarte, P.D., Owens, R., 2010. Housing externalities. Journal of Political Economy 118, 485-535.

Shleifer, A., Vishny, R., 2011. Fire sales in finance and macroeconomics. Journal of Economic Perspectives 25, 29-48. 


\section{Table 1, Descriptive statistics}

We report descriptive statistics for all transactions, and transactions in estates that are classified as liquid or not, respectively. A liquid estate is defined as estates with 1,000 or more transactions over our sample period, equivalent to around 5 transactions per month. Panel A reports transaction characteristics: Price is in million HKD (one USD equals $7.78 \mathrm{HKD}$ ), Size is measured in square feet (one square meter equals 10.76 square feet), Price per square feet is in HKD, and age is measured in years. New unit is an indicator for primary transactions. Carpark is an indicator for whether the transaction includes allocated space in the carpark. Panels B, C, and D report the distribution of transactions on territory (i.e. region), year, and quarter of year, respectively. ${ }^{* * *}$ denotes significance at the $1 \%$ level.

\begin{tabular}{|c|c|c|c|c|}
\hline & \multirow[t]{2}{*}{ All } & \multicolumn{2}{|c|}{ Liquid estate } & \multirow{2}{*}{$\begin{array}{r}\text { Difference } \\
(1)-(2)\end{array}$} \\
\hline & & $\begin{array}{l}\text { Yes } \\
\text { (1) }\end{array}$ & $\begin{array}{l}\text { No } \\
\text { (2) }\end{array}$ & \\
\hline \multicolumn{5}{|c|}{ A. Transaction characteristics } \\
\hline Price (million HKD) & 4.23 & 3.84 & 4.80 & $0.97^{* * *}$ \\
\hline Size (square feet) & 606.3 & 591.7 & 627.7 & $-36.0^{* * *}$ \\
\hline Price per square feet (HKD) & $6,209.0$ & $6,033.2$ & $6,467.2$ & $-433.2^{* * *}$ \\
\hline Block age (years) & 14.2 & 10.5 & 19.7 & $-9.2^{* * *}$ \\
\hline New unit $(\%)$ & 17.5 & 22.6 & 10.2 & $12.4^{* * *}$ \\
\hline Carpark $(\%)$ & 6.5 & 2.3 & 12.7 & $-10.4^{* * *}$ \\
\hline \multicolumn{5}{|l|}{ B. Territory (\%) } \\
\hline Hong Kong Island & 22.4 & 11.8 & 37.9 & \\
\hline Kowloon & 27.7 & 23.4 & 33.9 & \\
\hline New Territories & 50.0 & 64.8 & 28.2 & \\
\hline \multicolumn{5}{|l|}{ C. Year } \\
\hline 2000 & 48,302 & 28,847 & 19,455 & \\
\hline 2001 & 55,430 & 33,805 & 21,624 & \\
\hline 2002 & 54,390 & 35,529 & 18,861 & \\
\hline 2003 & 56,801 & 37,856 & 18,945 & \\
\hline 2004 & 79,426 & 50,508 & 28,918 & \\
\hline 2005 & 75,821 & 46,191 & 29,630 & \\
\hline 2006 & 61,276 & 35,178 & 26,098 & \\
\hline 2007 & 100,882 & 59,790 & 41,092 & \\
\hline 2008 & 66,322 & 38,695 & 27,627 & \\
\hline 2009 & 95,448 & 56,179 & 39,269 & \\
\hline 2010 & 103,938 & 60,633 & 43,305 & \\
\hline 2011 & 63,552 & 35,547 & 28,005 & \\
\hline 2012 & 65,072 & 38,277 & 26,795 & \\
\hline 2013 & 37,558 & 21,675 & 15,883 & \\
\hline 2014 & 51,242 & 29,629 & 21,613 & \\
\hline 2015 & 41,462 & 20,646 & 20,816 & \\
\hline \multicolumn{5}{|l|}{ D. Quarter } \\
\hline First & 271,779 & 162,701 & 109,078 & \\
\hline Second & 272,399 & 161,750 & 111,649 & \\
\hline Third & 260,824 & 156,336 & 104,488 & \\
\hline Fourth & 251,920 & 149,199 & 102,721 & \\
\hline $\mathrm{N}$ & $1,056,922$ & 628,986 & 427,936 & \\
\hline
\end{tabular}




\section{Table 2, Sample of haunted houses}

We report the composition of the sample of haunted houses in liquid estates between 2000 and 2015. A house becomes haunted if a murder, suicide, accident or some other unnatural death occurs. Panel A reports the cause of death. Panel $\mathrm{B}$ reports the distribution of unnatural deaths by territory (i.e. region). Panel $\mathrm{C}$ reports the distribution of unnatural deaths by year. Panel D reports the number of transactions involving: haunted units, units on the haunted floor (excluding the haunted unit), units in the haunted block (excluding the haunted floor), units in the haunted estate (excluding the haunted block), and non-haunted units.

\begin{tabular}{|c|c|c|}
\hline & $\mathbf{N}$ & $\%$ \\
\hline \multicolumn{3}{|l|}{ A. Cause of deaths } \\
\hline Murder & 21 & $2.0 \%$ \\
\hline Suicide & 910 & $88.2 \%$ \\
\hline Accidents & 73 & $7.1 \%$ \\
\hline Other & 28 & $2.7 \%$ \\
\hline \multicolumn{3}{|l|}{ B. Territory } \\
\hline Hong Kong Island & 199 & $19.3 \%$ \\
\hline Kowloon & 246 & $23.8 \%$ \\
\hline New Territories & 587 & $56.9 \%$ \\
\hline \multicolumn{3}{|l|}{ C. Year } \\
\hline 2000 & 56 & $5.4 \%$ \\
\hline 2001 & 70 & $6.8 \%$ \\
\hline 2002 & 69 & $6.7 \%$ \\
\hline 2003 & 90 & $8.7 \%$ \\
\hline 2004 & 73 & $7.1 \%$ \\
\hline 2005 & 70 & $6.8 \%$ \\
\hline 2006 & 61 & $5.9 \%$ \\
\hline 2007 & 47 & $4.6 \%$ \\
\hline 2008 & 64 & $6.2 \%$ \\
\hline 2009 & 62 & $6.0 \%$ \\
\hline 2010 & 61 & $5.9 \%$ \\
\hline 2011 & 48 & $4.7 \%$ \\
\hline 2012 & 63 & $6.1 \%$ \\
\hline 2013 & 73 & $7.1 \%$ \\
\hline 2014 & 71 & $6.9 \%$ \\
\hline 2015 & 54 & $5.2 \%$ \\
\hline $\mathrm{N}$ & 1,032 & $100 \%$ \\
\hline \multicolumn{3}{|l|}{ D. Transactions } \\
\hline Haunted units & 761 & $0.1 \%$ \\
\hline Haunted floors & 3,606 & $0.3 \%$ \\
\hline Haunted blocks & 99,258 & $9.4 \%$ \\
\hline Haunted estates & 267,816 & $25.3 \%$ \\
\hline Non-haunted & 685,477 & $64.9 \%$ \\
\hline $\mathrm{N}$ & $1,056,918$ & $100 \%$ \\
\hline
\end{tabular}


Table 3, Difference-in-differences estimate of haunted houses on price per square feet

This table reports the average price per square feet before and after a unit becomes haunted. Panel A shows the average price per square feet for transactions occurring one year before to one year after, whereas Panels B and C report the same for the period of two and three years before and after, respectively. We report the effect of haunted units, units on the haunted floor (excluding the haunted unit), and for units in the haunted block (excluding the haunted floor). To control for time-trends in prices we also report the average price per square foot in the same district, and provide a difference-in-differences estimate of the effect of haunted houses on the price per square feet.

\begin{tabular}{|c|c|c|c|c|c|c|c|c|c|}
\hline \multirow[t]{2}{*}{ Window } & \multicolumn{3}{|c|}{ Unit } & \multicolumn{3}{|c|}{ Floor } & \multicolumn{3}{|c|}{ Block } \\
\hline & \multicolumn{2}{|c|}{ Price per square foot } & $\begin{array}{c}\% \\
\text { Difference }\end{array}$ & \multicolumn{2}{|c|}{ Price per square foot } & $\begin{array}{c}\% \\
\text { Difference }\end{array}$ & \multicolumn{2}{|c|}{ Price per square foot } & $\begin{array}{c}\% \% \\
\text { Difference }\end{array}$ \\
\hline \multicolumn{10}{|c|}{ A. One year before to one year after } \\
\hline Before & 4,898 & 5,245 & $-7 \%$ & 5,196 & 5,534 & $-6 \%$ & 5,335 & 5,632 & $-5 \%$ \\
\hline After & 4,785 & 5,717 & $-16 \%$ & 5,151 & 5,569 & $-8 \%$ & 5,401 & 5,788 & $-7 \%$ \\
\hline Difference & $-2 \%$ & $9 \%$ & $-11 \%$ & $-1 \%$ & $1 \%$ & $-1 \%$ & $1 \%$ & $3 \%$ & $-2 \%$ \\
\hline Before & 5,028 & 5,172 & $-3 \%$ & 4,987 & 5,286 & $-6 \%$ & 5,205 & 5,458 & $-5 \%$ \\
\hline After & 4,587 & 5,512 & $-17 \%$ & 5,196 & 5,746 & $-10 \%$ & 5,500 & 5,897 & $-7 \%$ \\
\hline Difference & $-9 \%$ & $7 \%$ & $-15 \%$ & $4 \%$ & $9 \%$ & $-5 \%$ & $6 \%$ & $8 \%$ & $-2 \%$ \\
\hline \multicolumn{10}{|c|}{ C. Three years before to three years after } \\
\hline Before & 5,182 & 5,203 & $0 \%$ & 4,961 & 5,234 & $-5 \%$ & 5,199 & 5,401 & $-4 \%$ \\
\hline
\end{tabular}




\section{Table 4, Spillover effects of haunted houses on price}

This table shows the spillover effect of haunted houses on transaction prices. The dependent variable is log. of the transaction price in million HKD. In Column 1 to 4 the sample consists of transactions in all estates, whereas the sample in Column 5 only consists of new estates that were constructed during the sample period. Haunted unit is an indicator for haunted units (units in which an unnatural death occurred). Haunted floor is an indicator for units on the same floor as the haunted unit, but is set to zero for the haunted unit. Haunted block is an indicator for units on the same block as the haunted unit. It is set to the count of the number of haunted units in the block, but is set to zero for haunted units and all units on a haunted floor. Haunted estate is an indicator for units on the same estate as the haunted unit. It is set to the count of the number of haunted units in the estate, but is set to zero for haunted units, units on the haunted floor, and units on the haunted block. Same block, proximity to haunted floor (1-3) is an indicator for units that are 1 to 3 floors above or below a haunted floor in a haunted block. Same block, proximity to haunted floor (4-6) is an indicator for units that are 4 to 6 floors above or below a haunted floor in a haunted block. Same estate, neighbor to baunted block is an indicator for units that are in a block that is the neighbor to a haunted block. Size is the size of the unit measured in square feet. Age is the block age measured years. New unit is an indicator for primary transactions. Carpark is an indicator for whether the transaction includes allocated space in the carpark. All specifications include unit fixed-effects and year-month fixedeffects. Standard errors are clustered at the unit level, and reported in parenthesis. ***, ** and * indicate statistical significance at the 1,5 , and 10 percent level, respectively.

\begin{tabular}{|c|c|c|c|c|c|}
\hline \multirow[t]{2}{*}{ Sample } & \multicolumn{4}{|c|}{ All estates } & \multirow{2}{*}{$\begin{array}{c}\text { New estates } \\
(5) \\
\end{array}$} \\
\hline & (1) & (2) & (3) & (4) & \\
\hline Haunted unit & $\begin{array}{c}-0.1979^{* * *} \\
(0.0241)\end{array}$ & $\begin{array}{c}-0.1976^{* * *} \\
(0.0241)\end{array}$ & $\begin{array}{c}-0.1903^{* * *} \\
(0.0242)\end{array}$ & $\begin{array}{l}-0.1901^{* * * *} \\
(0.0242)\end{array}$ & $\begin{array}{l}-0.1894^{* * *} \\
(0.0419)\end{array}$ \\
\hline Haunted floor & $\begin{array}{l}-0.0967^{* * *} \\
(0.0084)\end{array}$ & $\begin{array}{c}-0.0964^{* * *} \\
(0.0084)\end{array}$ & $\begin{array}{c}-0.0890^{* * *} \\
(0.0083)\end{array}$ & $\begin{array}{c}-0.0887^{* * *} \\
(0.0084)\end{array}$ & $\begin{array}{c}-0.0785^{* * *} \\
(0.0135)\end{array}$ \\
\hline Haunted block & $\begin{array}{c}-0.0707^{* * *} \\
(0.0017)\end{array}$ & $\begin{array}{c}-0.0672^{* * *} \\
(0.0018)\end{array}$ & $\begin{array}{c}-0.0650^{* * * *} \\
(0.0017)\end{array}$ & $\begin{array}{c}-0.0616^{* * * *} \\
(0.0018)\end{array}$ & $\begin{array}{c}-0.0398^{* * *} \\
(0.0025)\end{array}$ \\
\hline Haunted estate & $\begin{array}{c}-0.0138^{* * *} \\
(0.0003)\end{array}$ & $\begin{array}{c}-0.0139^{* * * *} \\
(0.0003)\end{array}$ & $\begin{array}{c}-0.0127^{* * * *} \\
(0.0003)\end{array}$ & $\begin{array}{c}-0.0128^{* * * *} \\
(0.0003)\end{array}$ & $\begin{array}{c}-0.0137^{* * *} \\
(0.0007)\end{array}$ \\
\hline Same block, proximity to haunted floor (1-3 floors) & & $\begin{array}{c}-0.0212^{* * *} \\
(0.0040)\end{array}$ & & $\begin{array}{c}-0.0205^{* * *} \\
(0.0039)\end{array}$ & $\begin{array}{c}-0.0185^{* * *} \\
(0.0062)\end{array}$ \\
\hline Same block, proximity to haunted floor (4-6 floors) & & $\begin{array}{c}-0.0141^{* * *} \\
(0.0041)\end{array}$ & & $\begin{array}{c}-0.0134^{* * *} \\
(0.0041)\end{array}$ & $\begin{array}{l}-0.0094 \\
(0.0061)\end{array}$ \\
\hline Same estate, neighbor to haunted block & & & $\begin{array}{c}-0.0195^{* * *} \\
(0.0010)\end{array}$ & $\begin{array}{c}-0.0195^{* * *} \\
(0.0010)\end{array}$ & $\begin{array}{l}-0.0220^{* * *} \\
(0.0023)\end{array}$ \\
\hline Size & $\begin{array}{l}0.0002^{* *} \\
(0.0001)\end{array}$ & $\begin{array}{l}0.0002^{* *} \\
(0.0001)\end{array}$ & $\begin{array}{l}0.0002^{* *} \\
(0.0001)\end{array}$ & $\begin{array}{l}0.0002^{* *} \\
(0.0001)\end{array}$ & $\begin{array}{c}0.0002 \\
(0.0001)\end{array}$ \\
\hline Age & $\begin{array}{l}-0.0014 \\
(0.0019)\end{array}$ & $\begin{array}{l}-0.0013 \\
(0.0019)\end{array}$ & $\begin{array}{l}-0.0009 \\
(0.0019)\end{array}$ & $\begin{array}{l}-0.0009 \\
(0.0019)\end{array}$ & $\begin{array}{c}0.0137^{* * *} \\
(0.0018)\end{array}$ \\
\hline New unit & $\begin{array}{l}0.1591^{* * *} \\
(0.0015)\end{array}$ & $\begin{array}{l}0.1591^{* * *} \\
(0.0015)\end{array}$ & $\begin{array}{l}0.1608^{* * *} \\
(0.0015)\end{array}$ & $\begin{array}{l}0.1609^{* * *} \\
(0.0015)\end{array}$ & $\begin{array}{l}0.1002^{* * *} \\
(0.0019)\end{array}$ \\
\hline Carpark & $\begin{array}{l}0.0505^{* * * *} \\
(0.0049)\end{array}$ & $\begin{array}{l}0.0504^{* * *} \\
(0.0049)\end{array}$ & $\begin{array}{c}0.0504^{\text {**** }} \\
(0.0049)\end{array}$ & $\begin{array}{c}0.0504^{* * *} \\
(0.0049)\end{array}$ & $\begin{array}{c}0.0561^{* * *} \\
(0.0070)\end{array}$ \\
\hline Unit fixed-effects & Yes & Yes & Yes & Yes & Yes \\
\hline Year-month fixed effects & Yes & Yes & Yes & Yes & Yes \\
\hline $\begin{array}{l}\text { Adj. R-squared } \\
\mathrm{N}\end{array}$ & $\begin{array}{c}0.989 \\
1,056,918\end{array}$ & $\begin{array}{c}0.989 \\
1,056,918\end{array}$ & $\begin{array}{c}0.989 \\
1,056,918\end{array}$ & $\begin{array}{c}0.989 \\
1,056,918\end{array}$ & $\begin{array}{c}0.991 \\
368,394\end{array}$ \\
\hline
\end{tabular}




\section{Table 5, Decay in spillover effects}

This table estimates the decay in the spillover effect of haunted houses on transaction prices. The dependent variable is log. of the transaction price in million HKD. In Column 1 the sample consists of transactions in all estates, whereas the sample in Column 2 only consists of new estates that were constructed during the sample period. Haunted unit is an indicator for haunted units (units in which an unnatural death occurred). Haunted floor is an indicator for units on the same floor as the haunted unit, but is set to zero for the haunted unit. Haunted block is an indicator for units on the same block as the haunted unit. It is set to the count of the number of haunted units in the block, but is set to zero for haunted units and all units on a haunted floor. Haunted estate is an indicator for units on the same estate as the haunted unit. It is set to the count of the number of haunted units in the estate, but is set to zero for haunted units, units on the haunted floor, and units on the haunted block. Time is the difference between the transaction date and the date where the unit becomes haunted, measured in years. For the interaction with haunted block and haunted estate, we use the timing of the last event whenever there are multiple haunted units in a block or estate. Control variables include: size, age, new unit and carpark (see Table 4 for definitions). All specifications include unit fixed-effects and year-month fixed effects. Standard errors are clustered at the unit level, and reported in parenthesis. ${ }^{* * *},{ }^{* *}$ and $*$ indicate statistical significance at the 1, 5, and 10 percent level, respectively.

\begin{tabular}{lcc}
\hline Sample & All estates & New estates \\
(1) & $(2)$ & $-0.1775^{* * *}$ \\
Haunted unit & $-0.1926^{* * *}$ & $(0.0450)$ \\
Haunted unit * Time & $(0.0250)$ & -0.0092 \\
& 0.0052 & $(0.0146)$ \\
Haunted floor & $(0.0040)$ & $-0.0878^{* * *}$ \\
& $-0.1043^{* * *}$ & $(0.0159)$ \\
Haunted floor ${ }^{*}$ Time & $(0.0089)$ & 0.0005 \\
& $0.0036^{* *}$ & $(0.0039)$ \\
Haunted block & $(0.0015)$ & $-0.0458^{* * *}$ \\
& $-0.0826^{* * *}$ & $(0.0027)$ \\
Haunted block $*$ Time & $(0.0018)$ & $0.0020^{* * *}$ \\
& $-0.0007^{*}$ & $(0.0008)$ \\
Haunted estate & $(0.0004)$ & $-0.0212^{* * *}$ \\
Haunted estate $*$ Time & $-0.0223^{* * *}$ & $(0.0010)$ \\
& $(0.0003)$ & $0.0038^{* * *}$ \\
Control variables & $-0.0028^{* * *}$ & $(0.0007)$ \\
Unit fixed-effects & $(0.0003)$ & Yes \\
Year-month fixed effects & Yes & Yes \\
Adj. R-squared & Yes & Yes \\
N & Yes & 0.991 \\
& 0.989 & 368,394 \\
\hline
\end{tabular}




\section{Table 6, Cause of death and spillover effects}

This table shows the spillover effect of haunted houses on transaction prices, conditional on the cause of death. The dependent variable is log. of the transaction price in million HKD. In Column 1 replicates the baseline specification from Column 1 of Table 4, whereas Column 2 to 4 report results conditional on the cause of death: Column 2 report results for murder, Column 3 for suicides, and Colum 4 for accidents and other causes of deaths. Haunted unit is an indicator for haunted units (units in which an unnatural death occurred). Haunted floor is an indicator for units on the same floor as the haunted unit, but is set to zero for the haunted unit. Haunted block is an indicator for units on the same block as the haunted unit. It is set to the count of the number of haunted units in the block, but is set to zero for haunted units and all units on a haunted floor. Haunted estate is an indicator for units on the same estate as the haunted unit. It is set to the count of the number of haunted units in the estate, but is set to zero for haunted units, units on the haunted floor, and units on the haunted block. Control variables include: size, age, new unit and carpark (see Table 4 for definitions). All specifications include unit fixed-effects and year-month fixed effects. Standard errors are clustered at the unit level, and reported in parenthesis. ${ }^{* * *},{ }^{* *}$ and $*$ indicate statistical significance at the 1,5 , and 10 percent level, respectively.

\begin{tabular}{|c|c|c|c|c|}
\hline & \multirow{2}{*}{$\begin{array}{l}\text { All } \\
\text { (1) }\end{array}$} & \multicolumn{3}{|c|}{ Cause of death } \\
\hline & & $\begin{array}{c}\text { Murder } \\
\text { (2) }\end{array}$ & $\begin{array}{c}\text { Suicide } \\
\text { (3) }\end{array}$ & $\begin{array}{l}\text { Accident } \\
\text { and other } \\
(4)\end{array}$ \\
\hline Haunted unit & $\begin{array}{c}-0.1979^{* * *} \\
(0.0241)\end{array}$ & $\begin{array}{c}-0.3447^{* * *} \\
(0.1001)\end{array}$ & $\begin{array}{c}-0.2039^{* * *} \\
(0.0253)\end{array}$ & $\begin{array}{c}-0.1229^{*} \\
(0.0713)\end{array}$ \\
\hline Haunted floor & $\begin{array}{c}-0.0967^{* * *} \\
(0.0084)\end{array}$ & $\begin{array}{c}-0.1923^{* * *} \\
(0.0623)\end{array}$ & $\begin{array}{c}-0.1057^{* * *} \\
(0.0087)\end{array}$ & $\begin{array}{l}-0.0477^{*} \\
(0.0285)\end{array}$ \\
\hline Haunted block & $\begin{array}{c}-0.0707^{* * *} \\
(0.0017)\end{array}$ & $\begin{array}{c}-0.1015^{* * *} \\
(0.0092)\end{array}$ & $\begin{array}{c}-0.0815^{* * *} \\
(-0.0018)\end{array}$ & $\begin{array}{c}-0.0592^{* * *} \\
(0.0047)\end{array}$ \\
\hline Haunted estate & $\begin{array}{c}-0.0138^{* * *} \\
(0.0003)\end{array}$ & $\begin{array}{c}-0.0467^{* * *} \\
(0.0032)\end{array}$ & $\begin{array}{c}-0.0257^{* * *} \\
(0.0004)\end{array}$ & $\begin{array}{c}-0.0082^{* * *} \\
(0.0010)\end{array}$ \\
\hline Control variables & Yes & Yes & Yes & Yes \\
\hline Unit fixed-effects & Yes & Yes & Yes & Yes \\
\hline Year-month fixed effects & Yes & Yes & Yes & Yes \\
\hline Adj. R-squared & 0.989 & 0.989 & 0.989 & 0.989 \\
\hline $\mathrm{N}$ & $1,056,918$ & $1,056,918$ & $1,056,918$ & $1,056,918$ \\
\hline
\end{tabular}




\section{Table 7, Difference-in-differences estimate of haunted houses on liquidity (measured by fraction of units sold)}

This table reports the fraction of haunted units, haunted floors and haunted blocks that are sold before and after a unit become haunted. Panel A shows the fraction of units sold one year before to one year after death, whereas Panel B and C report the same for the period of two and three years before and after death, respectively. We report the fraction of units sold for haunted units, haunted floors (excluding the haunted unit), and haunted blocks (excluding the haunted unit and haunted floor). To control for time-trends in market liquidity we also report the fraction of units sold in the same district in the same time period, and provide a differencein-differences estimate of the effect of haunted houses on liquidity, measured by the fraction of units sold.

\begin{tabular}{|c|c|c|c|c|c|c|c|c|c|}
\hline \multirow[t]{2}{*}{ Window } & \multicolumn{3}{|c|}{ Unit } & \multicolumn{3}{|c|}{ Floor } & \multicolumn{3}{|c|}{ Block } \\
\hline & \multicolumn{2}{|c|}{ Fraction sold } & $\begin{array}{c}\% \\
\text { Difference }\end{array}$ & \multicolumn{2}{|c|}{ Fraction sold } & Difference & \multicolumn{2}{|c|}{ Fraction sold } & Difference \\
\hline
\end{tabular}

\section{A. One year before to one year after}

$\begin{array}{lcc}\text { Before } & 6.0 \% & 7.2 \% \\ \text { After } & 13.3 \% & 7.3 \%\end{array}$

Difference

$7.3 \%$
$0.1 \%$

\section{B. Two years before to two years after}

$\begin{array}{lll}\text { Before } & 7.7 \% & 7.2 \% \\ \text { After } & 12.5 \% & 7.3 \%\end{array}$

Difference

\section{$7.3 \%$}

$0.1 \%$

\section{$-1.2 \%$}

$$
6.0 \%
$$

$7.2 \%$

\section{$0.5 \%$}

$5.2 \%$

$4.7 \%$

\section{$6.4 \%$}

$6.5 \%$

$0.1 \%$

$7.5 \%$
$6.5 \%$
$-1.0 \%$

$1.2 \%$

$4.1 \%$

$2.9 \%$

\section{$7.8 \%$ \\ $6.4 \%$ \\ $-1.4 \%$}

$7.2 \%$

$7.3 \%$

$0.1 \%$

\section{$7.2 \%$}

$7.3 \%$

$0.1 \%$

$7.0 \%$

$7.1 \%$

$0.1 \%$

$-0.8 \%$
$-0.8 \%$
$0.0 \%$

$-0.8 \%$

$-0.8 \%$

$-1.1 \%$

$0.1 \%$

$7.0 \%$
$7.1 \%$
$0.1 \%$

Difference

$3.0 \%$

$0.1 \%$

$\begin{array}{ccc}6.9 \% & 7.2 \% & -0.3 \% \\ 6.4 \% & 7.3 \% & -0.9 \% \\ -0.5 \% & 0.1 \% & -0.6 \%\end{array}$

$\begin{array}{ccc}7.4 \% & 7.2 \% & 0.2 \% \\ 6.3 \% & 7.3 \% & -1.0 \% \\ -1.1 \% & 0.1 \% & -1.2 \%\end{array}$

$\begin{array}{ccc}7.8 \% & 7.0 \% & 0.8 \% \\ 6.1 \% & 7.1 \% & -1.0 \% \\ -1.7 \% & 0.1 \% & -1.8 \%\end{array}$




\section{Table 8, Causes of spillover effects: demand shock or supply shock (price pressure)}

This table examines whether the spillover effect of haunted houses on transaction prices is driven by demand shock or supply shock (price pressure) from the affected unit. The dependent variable is log. of the transaction price in million HKD. Haunted floor is an indicator for units on the same floor as the haunted unit, but is set to zero for the haunted unit. Haunted block is an indicator for units on the same block as the haunted unit. It is set to the count of the number of haunted units in the block, but is set to zero for haunted units and all units on a haunted floor. Haunted estate is an indicator for units on the same estate as the haunted unit. It is set to the count of the number of haunted units in the estate, but is set to zero for haunted units, units on the haunted floor, and units on the haunted block. Haunted unit sold takes the value one if the haunted unit is sold before a given transaction. In Column 1 we consider transactions of haunted units that occur in the period between the unnatural death and the transaction date of a given units. In Column 2 to 4 , we consider transactions of haunted units that occurred in the last year, last 3 years and last 5 years relative to the transaction date of a given unit, respectively. Control variables include: size, age, new unit and carpark (see Table 4 for definitions). All specifications include unit fixed-effects and year-month fixed-effects. Standard errors are clustered at the unit level, and reported in parenthesis. ***, ** and * indicate statistical significance at the 1, 5, and 10 percent level, respectively.

\begin{tabular}{|c|c|c|c|c|}
\hline & $\begin{array}{c}\text { Anytime } \\
(1)\end{array}$ & $\begin{array}{c}\text { Last year } \\
(2)\end{array}$ & $\begin{array}{c}\text { Last } 3 \text { years } \\
\text { (3) }\end{array}$ & $\begin{array}{c}\text { Last } 5 \text { years } \\
(4)\end{array}$ \\
\hline Haunted floor & $\begin{array}{c}-0.0993^{* * *} \\
(0.0094)\end{array}$ & $\begin{array}{c}-0.1000^{* * *} \\
(0.0062)\end{array}$ & $\begin{array}{c}-0.0976^{* * *} \\
(0.0077)\end{array}$ & $\begin{array}{c}-0.0933^{* * *} \\
(0.0088)\end{array}$ \\
\hline Haunted floor $*$ Haunted unit sold & $\begin{array}{l}-0.0016 \\
(0.0096)\end{array}$ & $\begin{array}{c}0.0061 \\
(0.0069)\end{array}$ & $\begin{array}{l}-0.0017 \\
(0.0080)\end{array}$ & $\begin{array}{l}-0.0093 \\
(0.0091)\end{array}$ \\
\hline Haunted block & $\begin{array}{c}-0.0847^{* * *} \\
(0.0016)\end{array}$ & $\begin{array}{c}-0.0721^{* * *} \\
(0.0016)\end{array}$ & $\begin{array}{c}-0.0747^{* * *} \\
(0.0013)\end{array}$ & $\begin{array}{c}-0.0798^{* * *} \\
(0.0015)\end{array}$ \\
\hline Haunted block * Haunted unit sold & $\begin{array}{c}0.0141^{* * *} \\
(0.0016)\end{array}$ & $\begin{array}{c}0.0017 \\
(0.0010)\end{array}$ & $\begin{array}{l}0.0038^{* * *} \\
(0.0012)\end{array}$ & $\begin{array}{c}0.0087^{* * *} \\
(0.0014)\end{array}$ \\
\hline Haunted estate & $\begin{array}{c}-0.0215^{* * *} \\
(0.0003)\end{array}$ & $\begin{array}{c}-0.0153^{* * *} \\
(0.0002)\end{array}$ & $\begin{array}{c}-0.0175^{* * *} \\
(0.0002)\end{array}$ & $\begin{array}{c}-0.0206^{* * *} \\
(0.0003)\end{array}$ \\
\hline Haunted estate $*$ Haunted unit sold & $\begin{array}{l}0.0079^{* * *} \\
(0.0003)\end{array}$ & $\begin{array}{l}0.0016^{* * *} \\
(0.0003)\end{array}$ & $\begin{array}{l}0.0043^{* * *} \\
(0.0002)\end{array}$ & $\begin{array}{l}0.0070^{* * *} \\
(0.0003)\end{array}$ \\
\hline $\begin{array}{l}\text { Control variables } \\
\text { Unit fixed-effects } \\
\text { Year-month fixed effects }\end{array}$ & $\begin{array}{l}\text { Yes } \\
\text { Yes } \\
\text { Yes }\end{array}$ & $\begin{array}{l}\text { Yes } \\
\text { Yes } \\
\text { Yes }\end{array}$ & $\begin{array}{l}\text { Yes } \\
\text { Yes } \\
\text { Yes }\end{array}$ & $\begin{array}{l}\text { Yes } \\
\text { Yes } \\
\text { Yes }\end{array}$ \\
\hline $\begin{array}{l}\text { Adj. R-squared } \\
\mathrm{N}\end{array}$ & $\begin{array}{c}0.989 \\
1,056,157\end{array}$ & $\begin{array}{c}0.989 \\
1,056,157\end{array}$ & $\begin{array}{c}0.989 \\
1,056,157\end{array}$ & $\begin{array}{c}0.989 \\
1,056,157\end{array}$ \\
\hline
\end{tabular}




\section{Table 9, Placebo test using deaths that occurred outside the residence of the deceased}

This table shows the spillover effect of haunted houses on transaction prices. The dependent variable is log. of the transaction price in million HKD. Column 1 reports coefficients using the treatment sample of 1,032 unnatural deaths coded in similar fashion as in the baseline specification of Column 1 of Table 4, whereas Column 2 reports coefficients from a placebo sample (coded in similar fashion) of 235 unnatural deaths that by definition occurs outside the deceased residence. The placebo sample consist of 183 deaths in traffic accidents, 23 accidental deaths during medical procedures, and 29 accidental deaths due to drowning while swimming in the ocean. Haunted unit is an indicator for haunted units (units in which an unnatural death occurred). Haunted floor is an indicator for units on the same floor as the haunted unit, but is set to zero for the haunted unit. Haunted block is an indicator for units on the same block as the haunted unit. It is set to the count of the number of haunted units in the block, but is set to zero for haunted units and all units on a haunted floor. Haunted estate is an indicator for units on the same estate as the haunted unit. It is set to the count of the number of haunted units in the estate, but is set to zero for haunted units, units on the haunted floor, and units on the haunted block. Control variables include: size, age, new unit and carpark (see Table 4 for definitions). All specifications include unit fixed-effects and year-month fixed effects. Standard errors are clustered at the unit level, and reported in parenthesis. ${ }^{* *},{ }^{* *}$ and $*$ indicate statistical significance at the 1,5 , and 10 percent level, respectively.

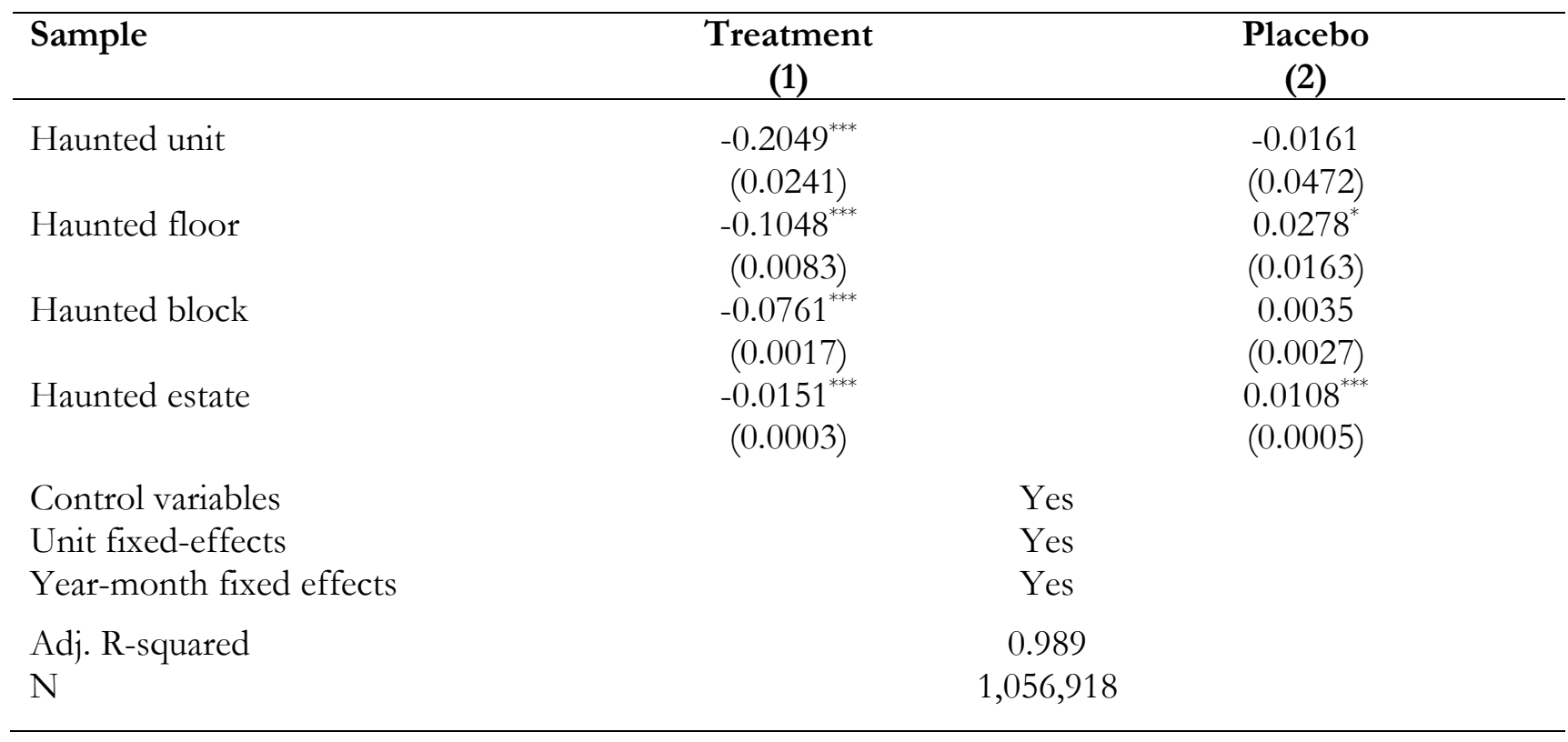




\section{Table 10, Spillovers in prices controlling for high-dimensional fixed-effects}

This table reports the spillovers in house prices with additional high dimensional fixed-effects capturing variation in house prices due to location and/or time effects. The dependent variable is log. of the transaction price in million HKD. Haunted floor is an indicator for units on the same floor as the haunted unit, but is set to zero for the haunted unit. Haunted block is an indicator for units on the same block as the haunted unit. It is set to the count of the number of haunted units in the block, but is set to zero for haunted units and all units on a haunted floor. Haunted estate is an indicator for units on the same estate as the haunted unit. It is set to the count of the number of haunted units in the estate, but is set to zero for haunted units, units on the haunted floor, and units on the haunted block. Haunted unit sold takes the value one if the haunted unit is sold before a given transaction. In Column 1 we report the results from the main specification in Column 1 of Table 4. Column 2 includes territory-year-quarter fixed effects. Column 3 includes territory-year-month fixed-effects. Column 4 includes district-year-quarter fixed effects, while Column 5 includes district-year-month fixedeffects. All specifications include the following (unreported) time-variant house characteristics: size, age, new unit and carpark (see Table 4 for definitions). All specifications include unit fixed-effects. Standard errors are clustered at the unit level, and reported in parenthesis. ${ }^{* *},{ }^{* *}$ and $*$ indicate statistical significance at the 1,5 , and 10 percent level, respectively.

\begin{tabular}{lccccc}
\hline & $\mathbf{( 1 )}$ & $\mathbf{( 2 )}$ & $\mathbf{( 3 )}$ & $\mathbf{( 4 )}$ & $\mathbf{( 5 )}$ \\
\hline Haunted unit & & & & & \\
& $-0.1979^{* * *}$ & $-0.1755^{* * *}$ & $-0.1743^{* * *}$ & $-0.1593^{* * *}$ & $-0.1601^{* * *}$ \\
Haunted floor & $(0.0241)$ & $(0.0220)$ & $(0.0222)$ & $(0.0215)$ & $(0.0213)$ \\
& $-0.0967^{* * *}$ & $-0.0624^{* * *}$ & $-0.0627^{* * *}$ & $-0.0537^{* * *}$ & $-0.0534^{* * *}$ \\
Haunted block & $(0.0084)$ & $(0.0080)$ & $(0.0080)$ & $(0.0074)$ & $(0.0073)$ \\
& $-0.0707^{* * *}$ & $-0.0480^{* * *}$ & $-0.0474^{* * *}$ & $-0.0413^{* * *}$ & $-0.0406^{* * *}$ \\
Haunted estate & $(0.0017)$ & $(0.0016)$ & $(0.0016)$ & $(0.0015)$ & $(0.0015)$ \\
& $-0.0138^{* * *}$ & $-0.0098^{* * *}$ & $-0.0096^{* * *}$ & $-0.0080^{* * *}$ & $-0.0077^{* * *}$ \\
& $(0.0003)$ & $(0.0003)$ & $(0.0003)$ & $(0.0003)$ & $(0.0003)$ \\
Control variables & & & & & \\
Unit fixed-effects & Yes & Yes & Yes & Yes & Yes \\
Year-month fixed effects & Yes & Yes & Yes & Yes & Yes \\
Territory-year-quarter fixed effects & Yes & No & No & No & No \\
Territory-year-month fixed effects & No & Yes & No & No & No \\
District-year-quarter fixed effects & No & No & Yes & No & No \\
District-year-month fixed effects & No & No & No & No & Yes \\
& & & & & \\
Adj. R-squared & 0.989 & 0.990 & 0.990 & 0.991 & 0.991 \\
N & $1,056,157$ & $1,056,157$ & $1,056,157$ & $1,056,157$ & $1,056,157$ \\
& & & &
\end{tabular}




\section{Figure 1, Market share of liquid estates}

This figure shows the market share of liquid estates between 2000 and 2015. A liquid estate is defined as estates with 1,000 or more transactions over our sample period, equivalent to around 5 transactions per month. We calculate the market share in liquid estates based on the number and value of transactions in each year.

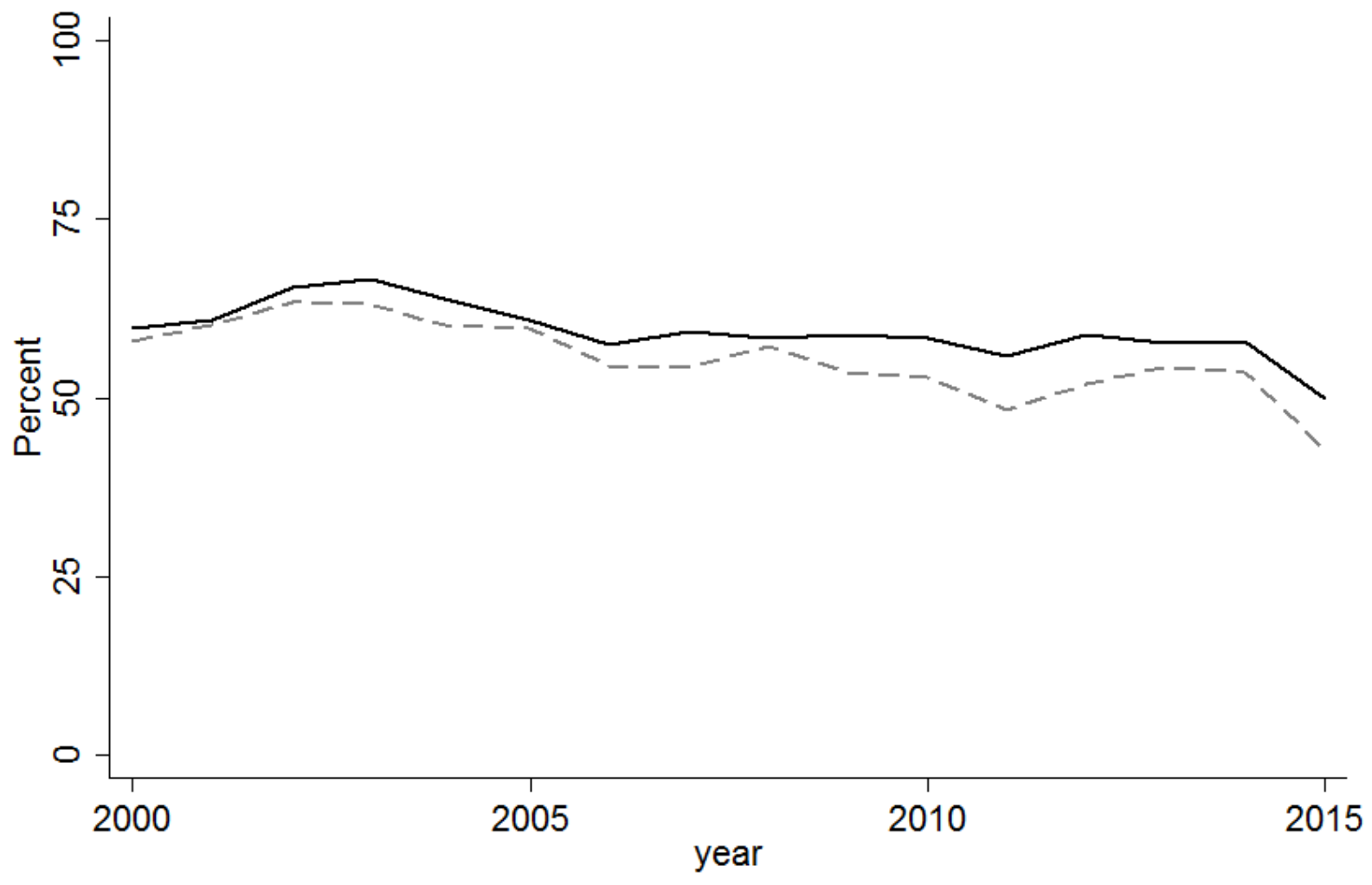

Number $\quad-----$ Value 
Figure 2, House price development, 2000-2015

This figure shows the average price per square for liquid and illiquid estates feet between 2000 and 2015. A liquid estate is defined as estates with 1,000 or more transactions over our sample period, equivalent to around 5 transactions per month.

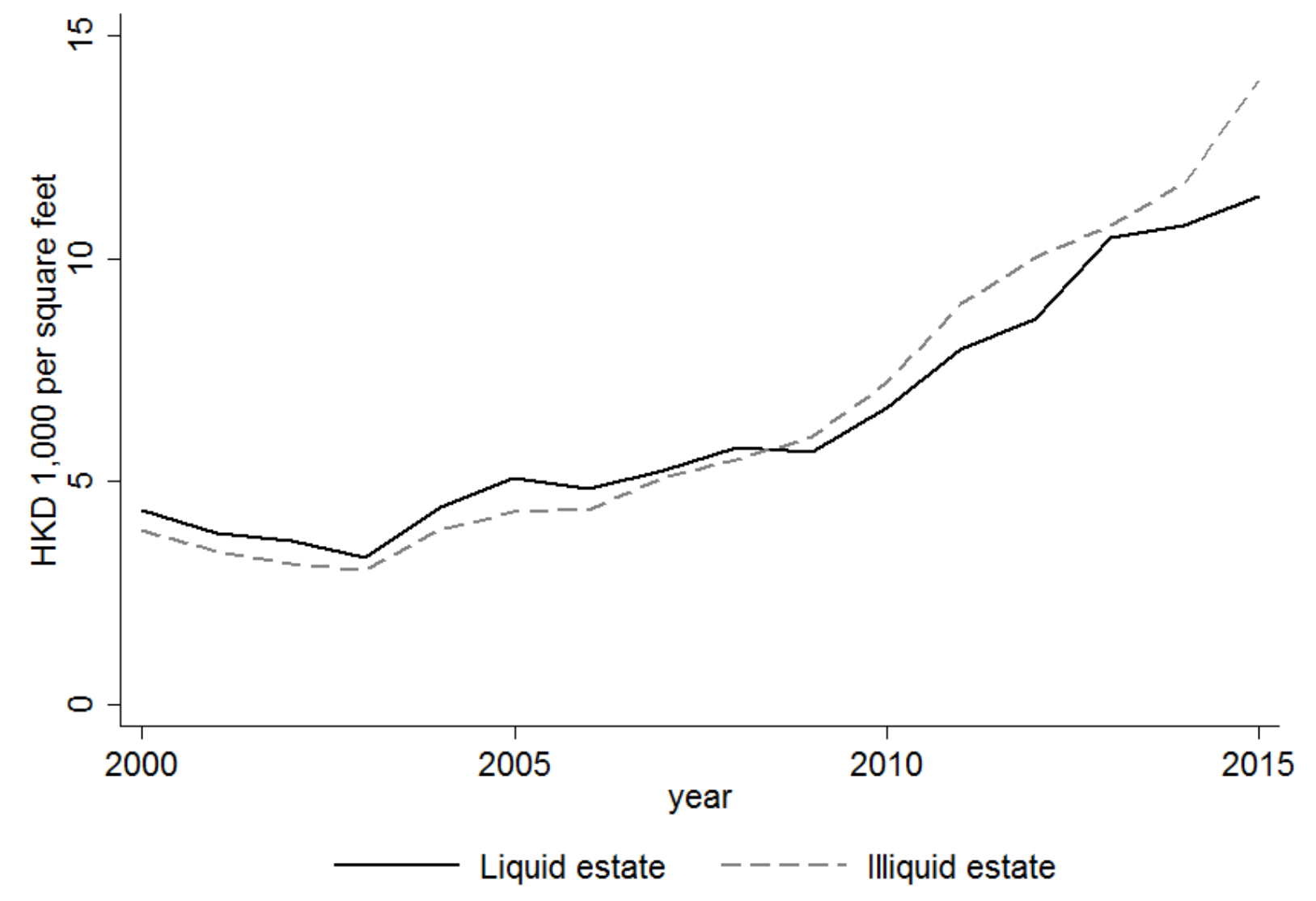




\section{Figure 3, Disentangling spillovers in prices: demand shock effect vs. supply shock (price pressure) effect}

This figure illustrates the decomposition of the spillover in prices into the demand shock effect vs. supply shock (price pressure) effect. Before a unit becomes haunted, the point $\mathrm{X}$ shows the price of its neighbour's house. The price of the neighbour's house drops to point $\mathrm{Y}$ when the unit becomes haunted, but is not sold. The price of the neighbour's house drops to point $Z$ when the unit becomes haunted and is about to be sold at fire sale price $Z$. The vertical distance from $X$ to $Z$ is the spillover in prices, which is decomposed into the effect from the demand shock caused by a shock to quality (X to $\mathrm{Y}$ ) and the effect from the supply shock (price pressure) caused because the haunted unit is sold at a fire sale price ( $\mathrm{Y}$ to $\mathrm{Z})$.

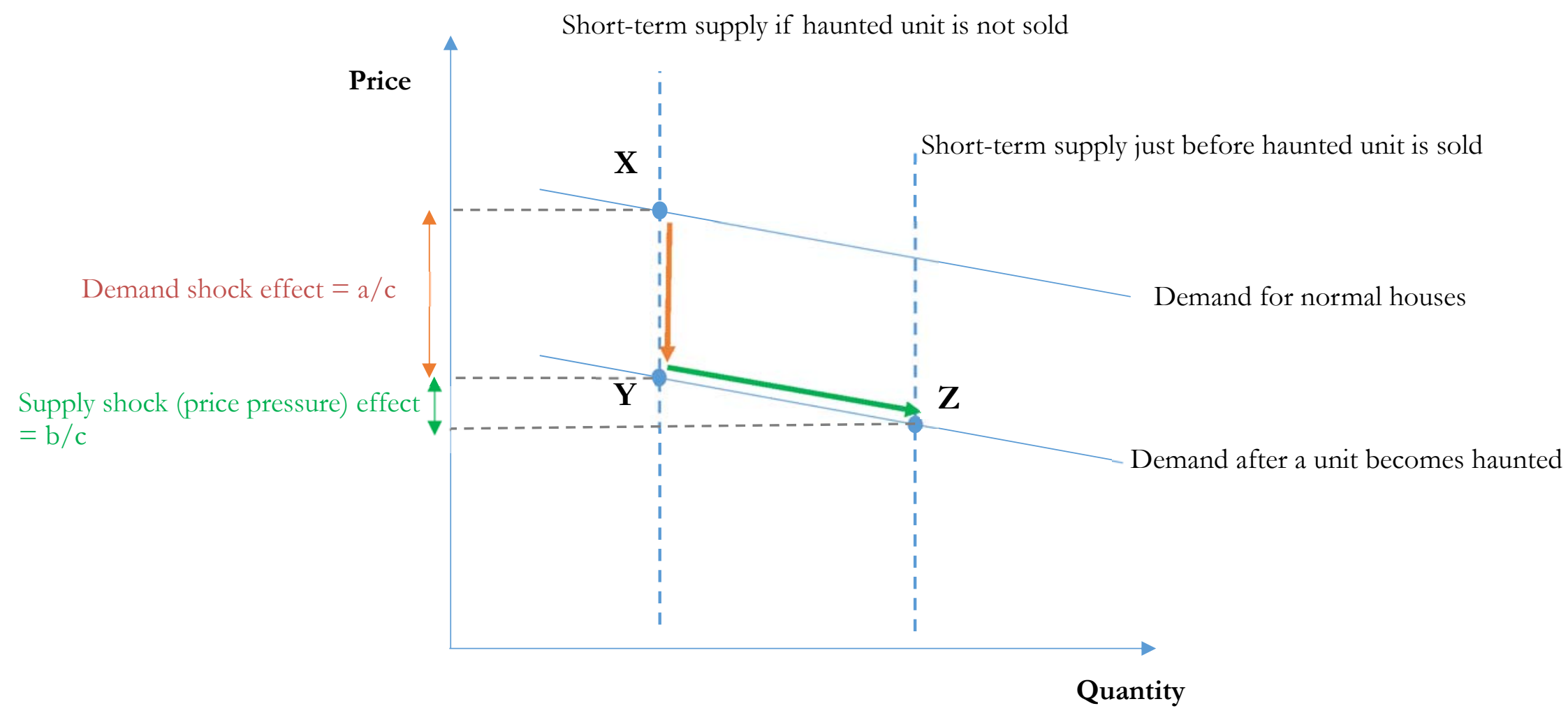




\section{Figure 4, Effect of haunted houses on liquidity (measured as fraction of units sold per year)}

This figure shows the fraction of haunted units sold per year before and after being haunted, the fraction of units on the same floor as the haunted unit (excluding the haunted unit) that are sold per year before and after, the fraction of units on the same block as the haunted unit (excluding the haunted unit and units on the haunted floor) that are sold per year before and after, and the fraction of units on the same estate as the haunted unit (excluding the haunted unit and units on the haunted floor and in the haunted block) that are sold per year before and after. The benchmark is the fraction of units in the same district that are sold per year before and after

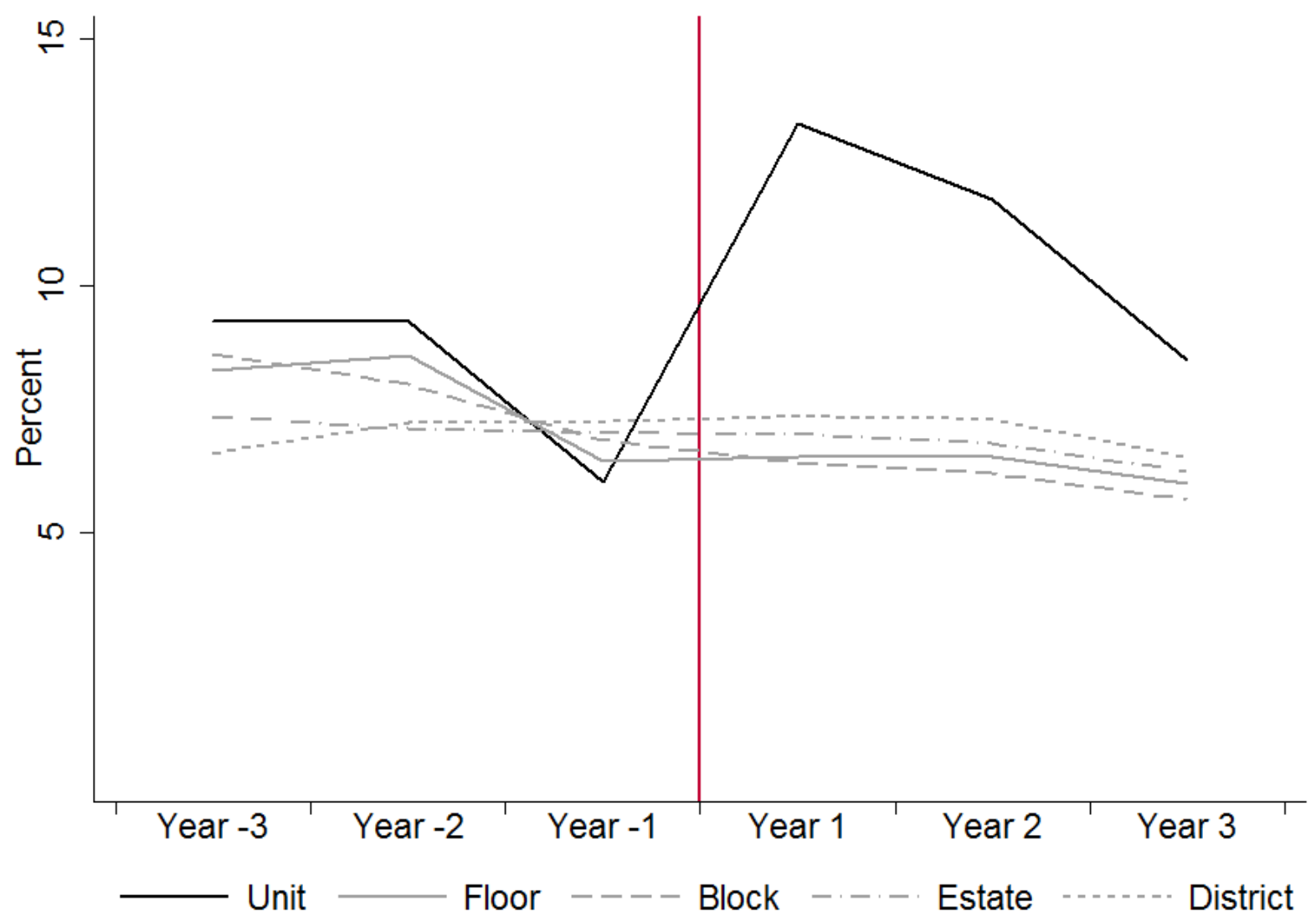




\section{Online Appendix for "Spillovers in Prices: The Curious Case of Haunted Houses"}

The following maps, photos and screenshots are included in this appendix:

- Appendix A1: Map of the 18 districts of Hong Kong

- Appendix A2: Map of Dawning Views in Fanling, North District, New Territories

- Appendix A3: Photo of the blocks of Dawning Views

- Appendix A4: Estate layout of Dawning Views

- Appendix A5: Floor plan of Floors 8-17 in Dawning Views

- Appendix B1: Screenshots of Squarefoot.com.hk

- Appendix B2: Screenshots of Spacious.com.hk 


\section{Appendix A1: The 18 Districts of Hong Kong}

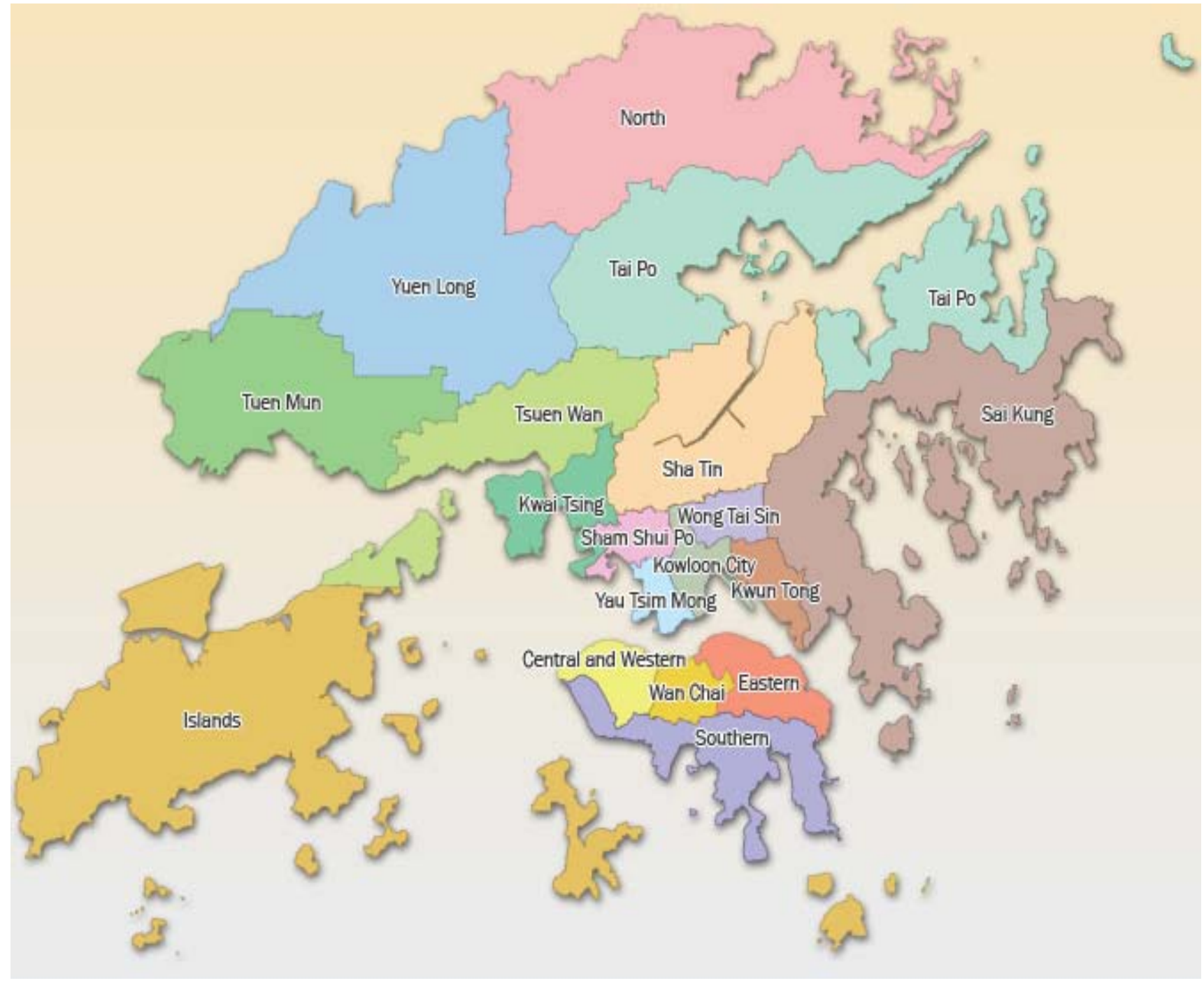


Appendix A2: Dawning Views in Fanling, North District, New Territories
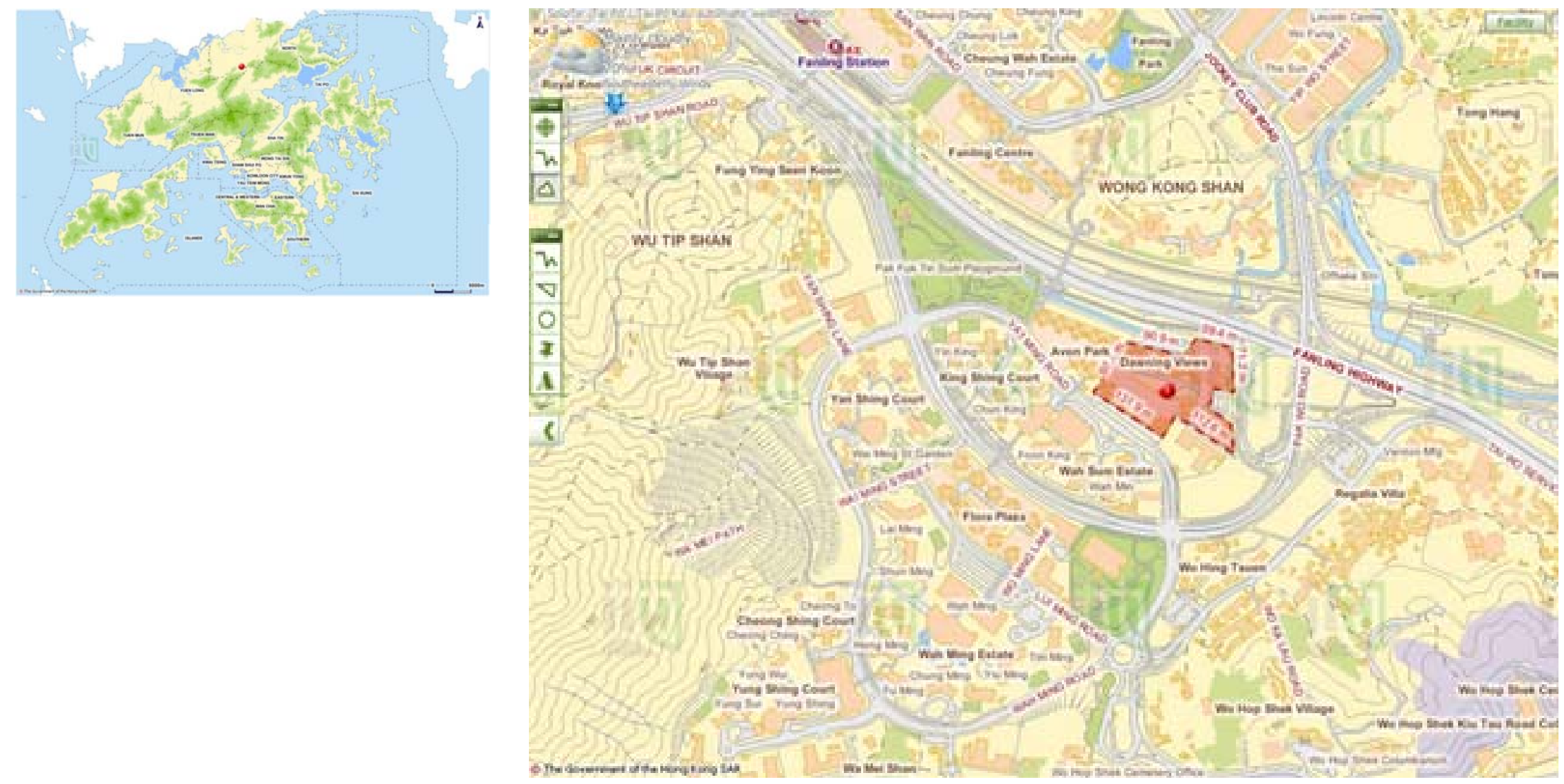


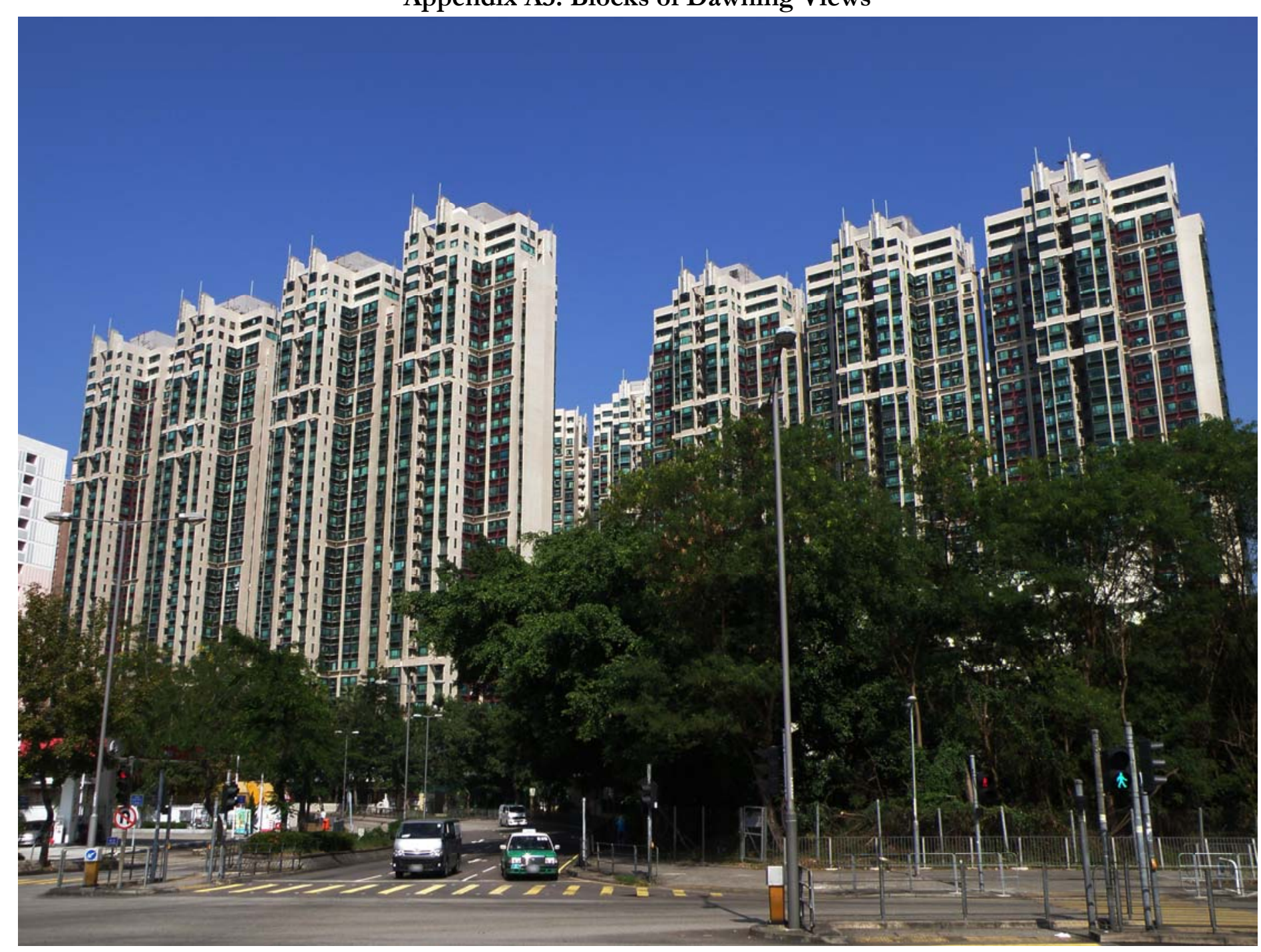


Appendix A4: Estate layout of Dawning Views

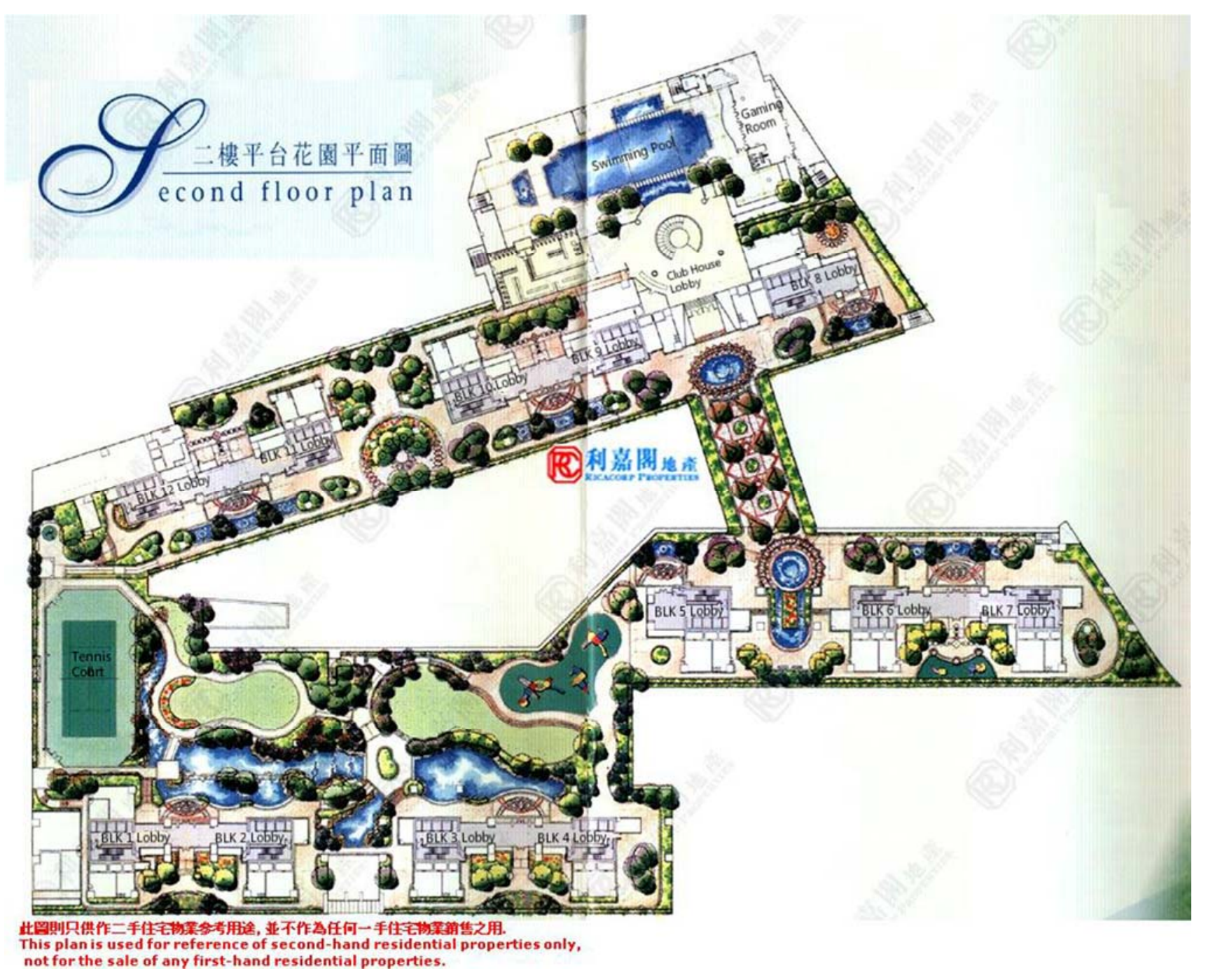


Appendix A5: Floor plan of Floors 8-17 in Block 12 in Dawning Views

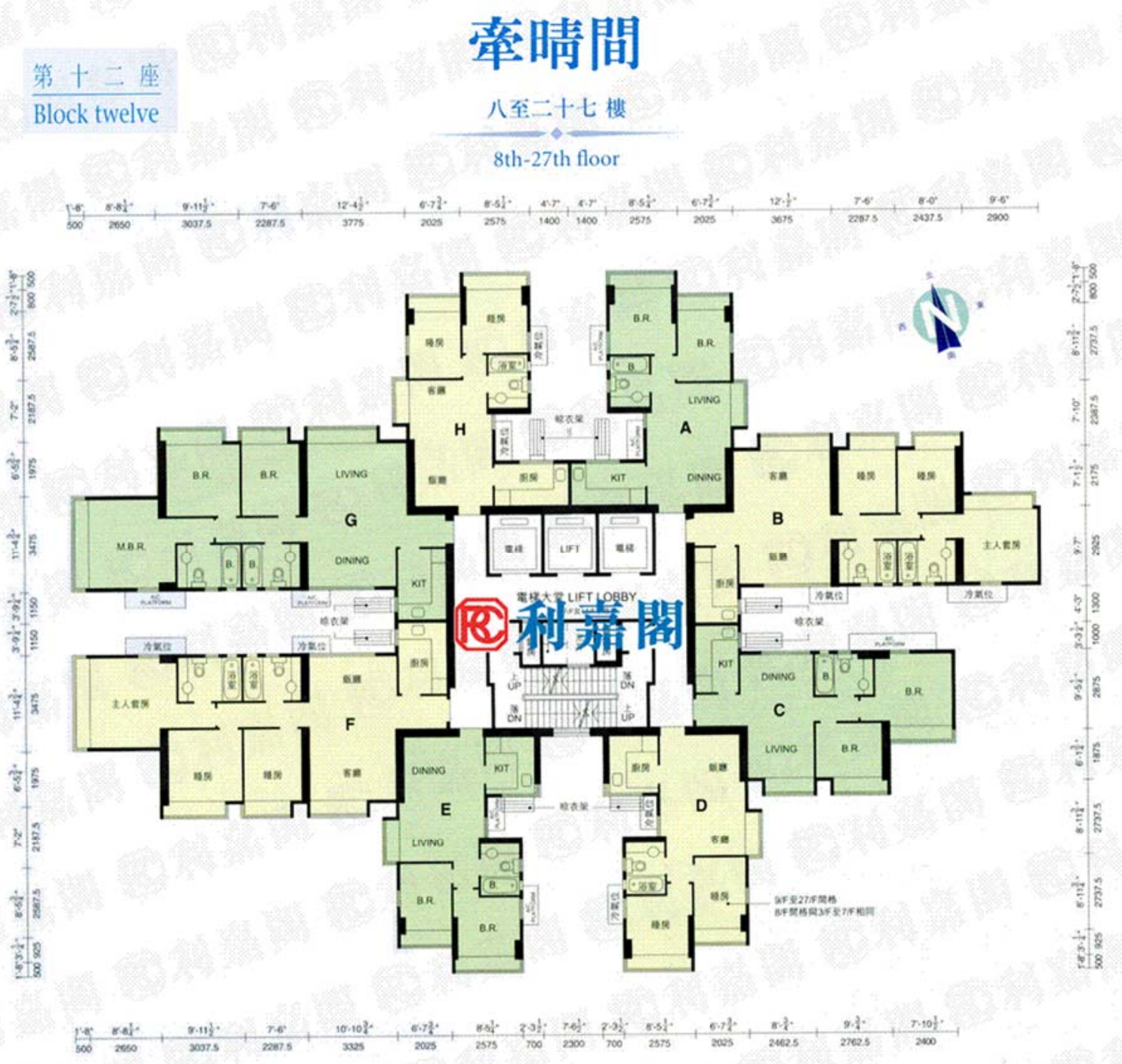

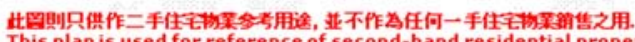

this plan is used for reference of second-hand residential properties only
not for the sale of any first-hand residential properties. 


0 Home Blog-Squarefoo $\times+$
$\leftarrow \rightarrow \circlearrowright \mid$ squarefoot.com.hk/home-blog $\quad \times$

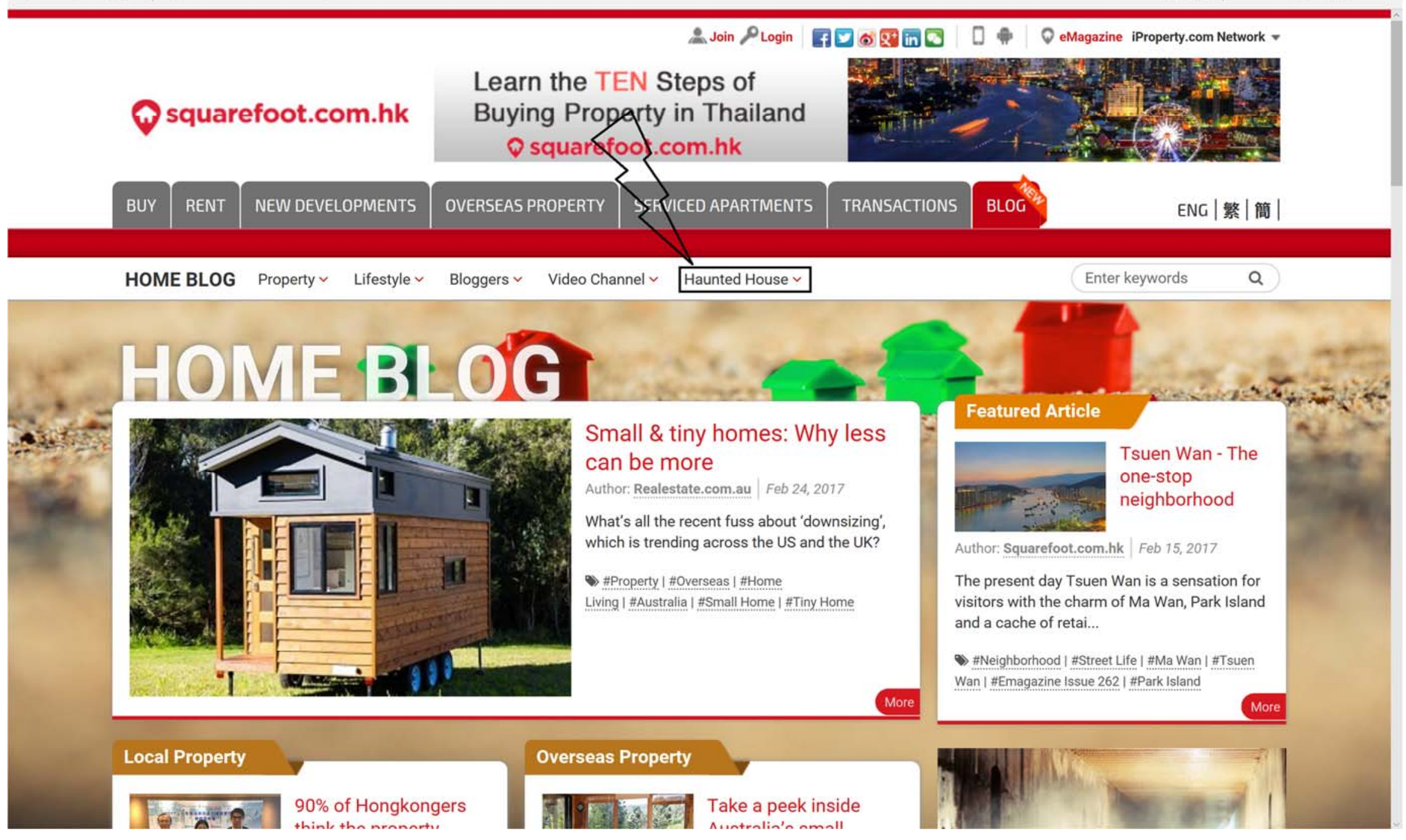




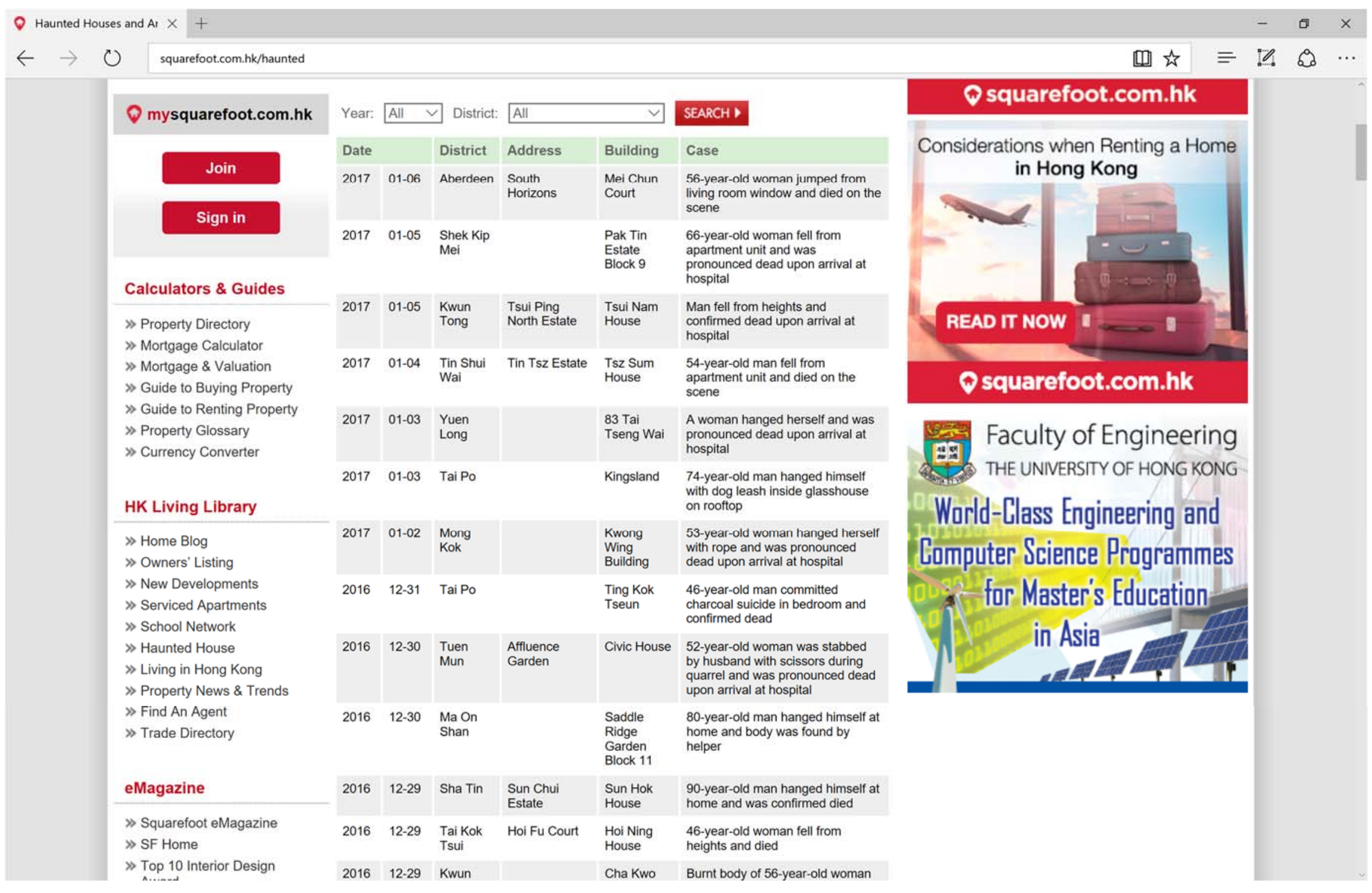


Appendix B2: Screenshots of Spacious.com.hk
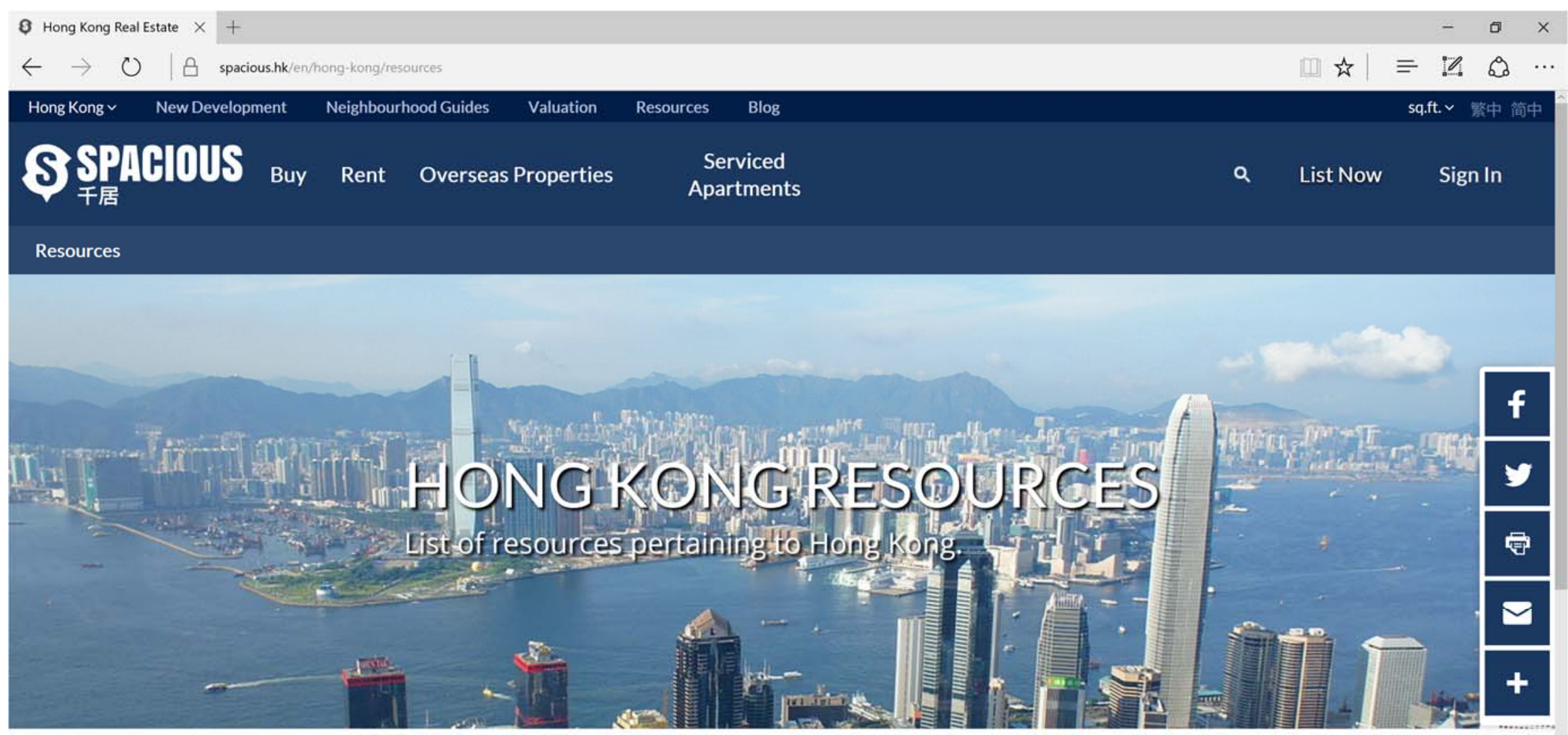

\section{(9) \\ Find all haunted houses in Hong Kong}

Schools

Find all schools in Hong Kong 


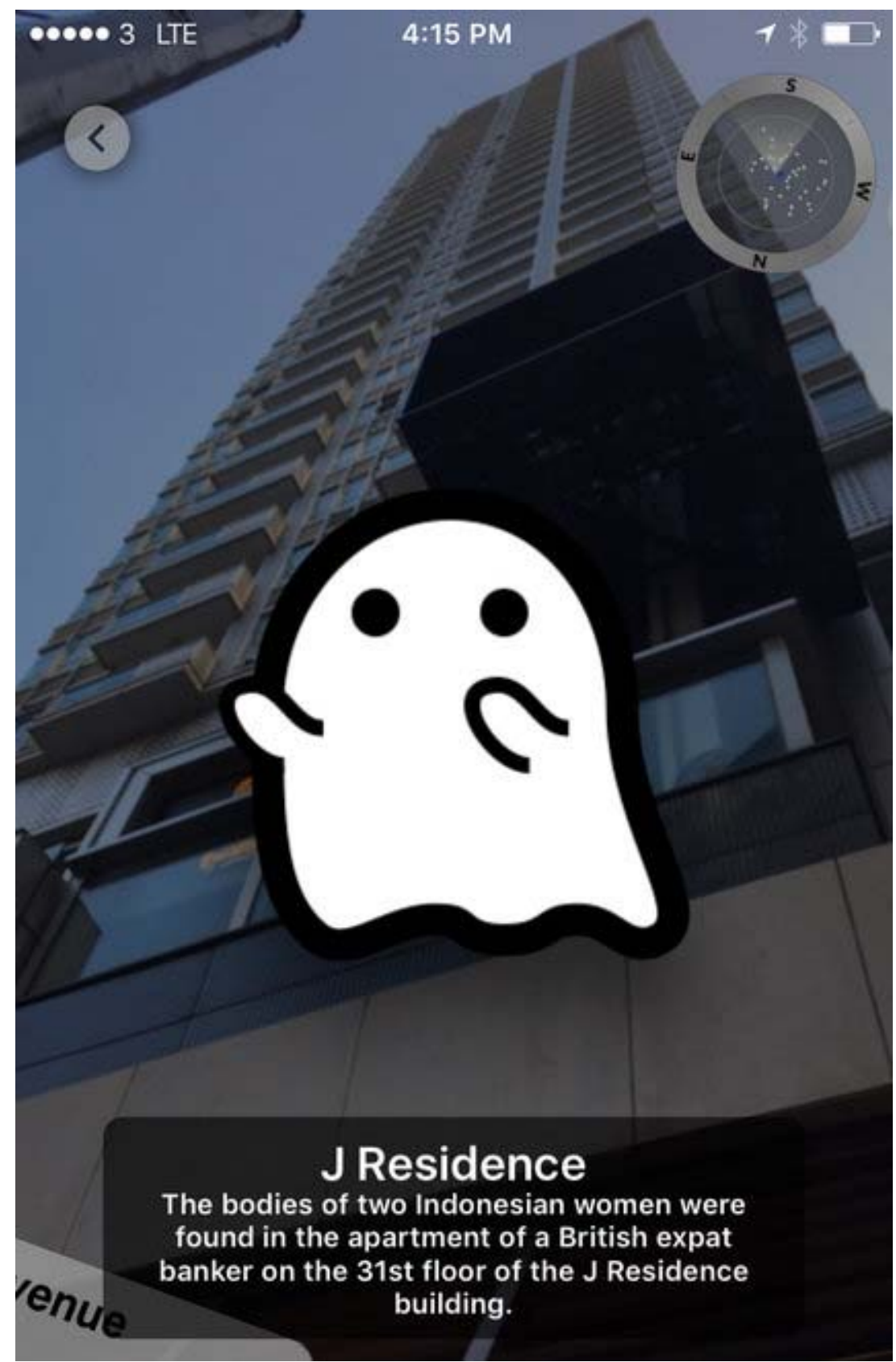




\section{SSPICHOUS}

\section{Select Neighbourhoods}

\section{Price}

Area $\checkmark$ AnyBeds

$\longdiv { \operatorname { M o r e } v }$

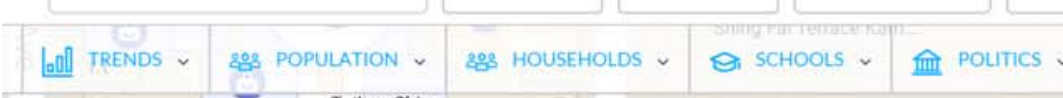

(5) $5^{\text {Gigasports }} \begin{array}{ll}\text { Taikoo Shing. } \\ \text { Horizon Gardens Yat.. }\end{array}$ 曰 (-) Shing Fai Terrace Yiu.

๑ Tai Koo Shing Rd

\section{SAVE SEARCH}

Q List Now

Sign In

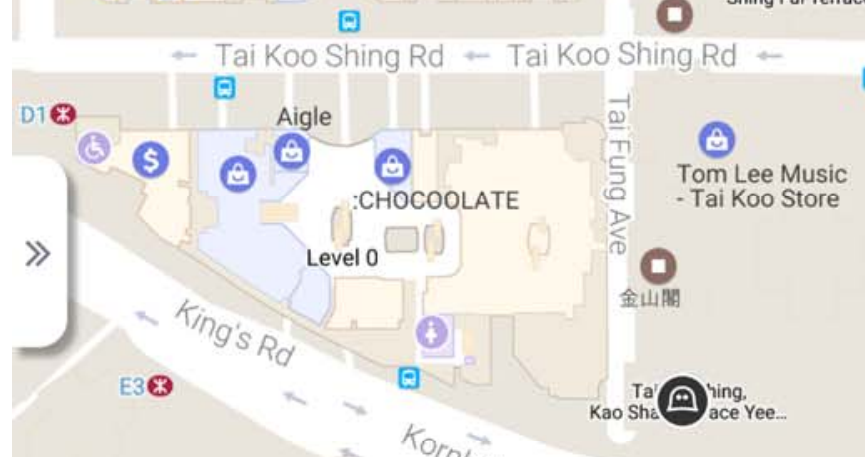

\section{@ HAUNTED}

\section{$\$$}

View

iew

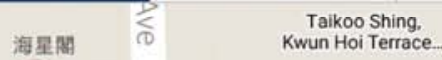

O

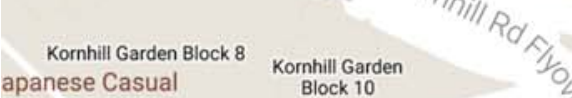
Kornhill Rd Ricacorp Properties (8) Hong Ons

Hang Lung Kornhill

Kornhill Block M Kornhill Block M

Taikoo Shing Tsui
Woo Terrace Po Yang

@

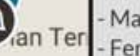

man in his 80 s jumped off the building due to sickness. out her husband's affair.

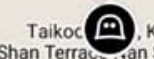
Taikoo Shing. Shan Terrace Tai.

Tai Koo Shing Road,

Former news anchor committed suicide by jumping off building.

A 61-year-old man with emotional problem jumped off the building

emale with depression first strangled her 10 years old son and hanged herself after she found 